Review

\title{
Solid State Gas Sensor Research in Germany - a Status Report
}

\author{
Ralf Moos $^{1, *}$, Kathy Sahner ${ }^{1}$, Maximilian Fleischer ${ }^{2}$, Ulrich Guth ${ }^{3}$, Nicolae Barsan ${ }^{4}$ and \\ Udo Weimar ${ }^{4}$ \\ ${ }^{1}$ Functional Materials Laboratory, University of Bayreuth, 95440 Bayreuth, Germany \\ 2 Siemens AG, Corporate Technology, CT PS 6, 81730 München, Germany \\ ${ }^{3}$ Kurt-Schwabe Research Institute Meinsberg, 04720 Ziegra-Knobelsdorf, Germany \\ ${ }^{4}$ Institute of Physical Chemistry, University of Tübingen, 72076 Tübingen, Germany \\ * Author to whom correspondence should be addressed; \\ E-Mail: Functional.Materials@Uni-Bayreuth.de; Tel.: +49-921-557401; Fax: +49-921-557405
}

Received: 25 March 2009; in revised form: 4 May 2009 / Accepted: 26 May 2009 /

Published: 3 June 2009

\begin{abstract}
This status report overviews activities of the German gas sensor research community. It highlights recent progress in the field of potentiometric, amperometric, conductometric, impedimetric, and field effect-based gas sensors. It is shown that besides step-by-step improvements of conventional principles, e.g. by the application of novel materials, novel principles turned out to enable new markets. In the field of mixed potential gas sensors, novel materials allow for selective detection of combustion exhaust components. The same goal can be reached by using zeolites for impedimetric gas sensors. Operando spectroscopy is a powerful tool to learn about the mechanisms in n-type and in ptype conductometric sensors and to design knowledge-based improved sensor devices. Novel deposition methods are applied to gain direct access to the material morphology as well as to obtain dense thick metal oxide films without high temperature steps. Since conductometric and impedimetric sensors have the disadvantage that a current has to pass the gas sensitive film, film morphology, electrode materials, and geometrical issues affect the sensor signal. Therefore, one tries to measure directly the Fermi level position either by measuring the gas-dependent Seebeck coefficient at high temperatures or at room temperature by applying a modified miniaturized Kelvin probe method, where surface adsorptionbased work function changes drive the drain-source current of a field effect transistor.
\end{abstract}

Keywords: impedance spectroscopy; mixed potential; $\mathrm{SnO}_{2} ; \mathrm{Ga}_{2} \mathrm{O}_{3} ;$ Kelvin probe; operando 


\section{Introduction}

Reliable detection of hazardous, harmful, or toxic gases has become a major issue due to more stringent environmental or safety regulations worldwide. Solid state gas sensors present a high potential for applications where the use of conventional analytical systems such as gas chromatography or optical detection (e.g. by infrared radiation) is prohibitively expensive. The interaction between the analyte in the surrounding gas phase and the sensor material is transduced as a measurable electrical signal that most often is a change in the conductance, capacitance, or potential of the active element. According to the respective measurement type, these sensor devices are commonly classified as "potentiometric", "amperometric", "conductometric", and so on.

During the past decades, a multitude of solid state sensors has been designed and brought to market, in particular in safety, automotive, process control, or household applications [1]. For many years, Taguchi-type metal-oxide sensors have been used for the detection of toxic or explosive gases [2]. Alternative sensor concepts for this purpose are based on electrochemical cells with polymer electrolytes. To ensure comfort of living spaces, capacitive polymer sensors measuring humidity are available [3]. Zirconia-based electrochemical cells monitor residual oxygen in automotive exhaust [4] or metal melts [5]. More recent developments comprise zeolite-based ammonia sensors [6] or mixedpotential $\mathrm{CO} / \mathrm{HC}$ sensors [7].

Nevertheless, research continues to meet the increasing demand for devices that present higher sensitivity, higher selectivity, and improved long-term stability at reduced cost. Due to Germany's cutting-edge pollution control regulations, the design of more efficient gas sensor devices has become a particularly active research field in this country.

In view of the numerous existing reviews on the field of gas sensing (e.g. [8,9]), the present contribution does not aim at giving a repetitive discussion of the well-established chemical gas sensors. Being a review paper in Sensors' special issue "State-of-the-Art Sensors Technology in Germany", more recent research topics are discussed that have received increased attention within the German sensor community for the past few years. Wherever applicable, the present review follows the common classification of sensors according to the measurand. However, an unambiguous assignment is not always possible for the novel trends discussed here. It should be annotated here that due to space limitations, the present review has been confined to potentiometric, amperometric, conductometric, and impedimetric principles, excluding optical principles or radio frequency-based principles. For the same reason, resonant sensor principles based on surface acoustic wave or bulk acoustic wave devices (SAW, BAW) or on quartz-crystal oscillators are not considered.

\section{Potentiometric Sensors}

Since the potential is not a function of geometry parameters, potentiometric devices are intrinsically independent from the sample dimensions. Various types of potentiometric sensors have been investigated for decades. Equilibrium or Nernstian electrochemical cells based on solid electrolytes, for example, may be employed for sensing chemical species in a very selective and accurate way. Among these candidates feature the stabilized zirconia air-to-fuel (or lambda) sensor for automotive applications [10] or the oxygen sensor (also zirconia-based) used in steelmaking [5]. In addition, several Non-Nernstian or mixed potential devices measuring gases in non-equilibrium conditions have 
been investigated. Very detailed reviews on electrochemical ceramic sensors discussing the respective mechanisms are available for example in [11-13]. The present section first presents recent trends developed for both subgroups. This discussion is followed by the discussion of a novel potentiometric sensor principle based on the direct thermoelectric effect.

\subsection{Nernst-type Sensors: Basic Considerations}

Potentiometric sensors using solid electrolytes are suited to measure gas components in different gas phases and liquid melts (e.g. molten steel):

0 Gas mixtures that contain free oxygen beside inert gases, e.g. $\mathrm{O}_{2}, \mathrm{~N}_{2}$

o Gas mixtures that are in chemical equilibrium, e.g. water gas

o Dissolved oxygen in molten metals (e.g. steel and copper)

The measurement of combustible volatile components in gases or as dissolved species in different liquid media gains importance, due to their widespread utilization in different energetic, chemical and biochemical processes and also due to the intensification of requirements for safety and quality control of technical, chemical and biochemical processes. These sensors are highly selective for certain components in a broader matrix of other gases, long-term stable and maintenance-free over years. Furthermore, they respond fast (ms-timescale) and are therefore an attractive tool in control loops. As a solid electrolyte gas-tight sintered ceramics in form of tubes, discs, planar substrates or thick films consisting of stabilized zirconia (e.g. yttria stabilized zirconia; YSZ) are utilized. Due to replacing zirconium ions by lower valent yttrium ions, oxide ion vacancies are generated. With increasing temperature, the transport of oxide ions $\left(\mathrm{O}^{2-}\right)$ becomes more and more possible. As a result, the electrical (ionic) conductivity increases exponentially with increasing temperature.

Figure 1. (a) potentiometric Nernst sensor (left). (b) mixed potential sensor (right).
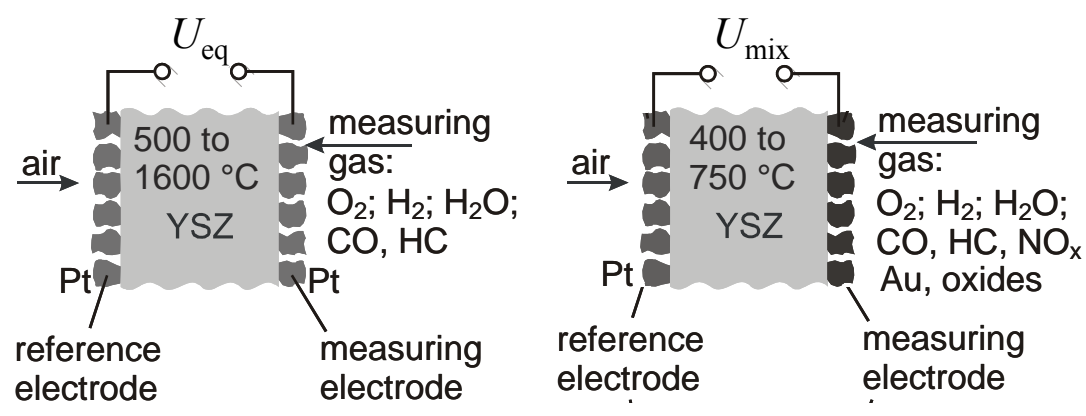

Potentiometric sensors for free oxygen and equilibrium oxygen (see Figure 1a) are very common in gas phases with established thermodynamic equilibria (e.g., $p\left(\mathrm{CO}_{2}\right) / p(\mathrm{CO})$ or, generally, the ratio of partial pressures of burnt and unburnt components). For that purpose, highly porous $\mathrm{Pt}$ is used as an electrode material (Figure 1a). Symbolized by $\mathrm{O}_{2}\left(\varphi^{\prime}{ }_{\mathrm{O} 2}\right)$, $\mathrm{Pt}\left|\left(\mathrm{ZrO}_{2}\right)_{0.84}\left(\mathrm{Y}_{2} \mathrm{O}_{3}\right)_{0.08}\right| \mathrm{Pt}, \mathrm{O}_{2}\left(\varphi^{\prime \prime}{ }_{\mathrm{O} 2}\right)$, such cells can be regarded as oxygen concentration cells. Depending on their electrode material, they work in a broad range of temperature $\left(400{ }^{\circ} \mathrm{C}\right.$ to $\left.1,600{ }^{\circ} \mathrm{C}\right)$ and oxygen partial pressures (10 bar to $10^{-20}$ bar). As a test probe, such sensors can be applied directly in high temperature processes, so that in-situ information may be obtained in real time. The generation of a cell voltage can be explained as follows: Oxygen will move from the side with high partial pressure toward the side with low partial pressure. 
That is impossible provided that the solid electrolyte is gas tight. In the tendency, oxygen can only move through the electrolyte as an oxide ion $\left(\mathrm{O}^{2-}\right)$. Oxygen takes up four electrons from electronic conducting material (here $\mathrm{Pt}$ ) and moves through the electrolyte (cathodic process, in right direction). On the side with lower oxygen partial pressure the reverse process takes place (anodic process, in left direction).

The cell reaction is the transfer of oxygen from one side to the other. Using the Kröger-Vink notation for defects this can be written: $1 / 2 \mathrm{O}_{2}(\mathrm{~g})+\mathrm{V}_{\mathrm{O}}{ }^{\bullet}(\mathrm{YSZ})+2 \mathrm{e}^{-}(\mathrm{Pt}) \leftrightarrow \mathrm{O}_{\mathrm{O}}$ (YSZ). In the case of an electrochemical equilibrium, the measured open circuit voltage or equilibrium voltage $U_{\text {eq }}$ or $E$ or emf can be calculated by the Nernst equation:

$$
E=-U_{e q}=\frac{R T}{4 F} \ln \frac{p_{O_{2}}^{\prime}}{p_{O_{2}}^{\prime \prime}}
$$

Therefore, such sensors are called Nernstian sensors. Air with defined humidity is used as a reference, e.g. air with $50 \%$ r.h. contains 20.63 vol.\% $\mathrm{O}_{2}$. In reducing gases in the chemical equilibrium (e.g. $\mathrm{H}_{2} / \mathrm{H}_{2} \mathrm{O} ; \mathrm{CO} / \mathrm{CO}_{2}$; water gas), the oxygen partial pressure is determined by the mass law constant $K_{\mathrm{p}}$ and this in turn depends on the temperature. In the case of $\mathrm{CO} / \mathrm{CO}_{2}$-mixtures, the cell voltage is obtained by inserting the temperature function of $\log K_{\mathrm{p}}=4.505-14700 \mathrm{~K} / \mathrm{T}$ into the Nernst equation.

With pure oxygen as $p{ }^{\mathrm{O} 2}$ :

$$
\begin{gathered}
\mathrm{E}\left(\mathrm{CO}, \mathrm{CO}_{2}\right) / \mathrm{mV}=-0.0496 \frac{\mathrm{T}}{\mathrm{K}} \lg \left[\mathrm{K}_{\mathrm{p}}\left(\frac{\mathrm{p}_{\mathrm{CO}_{2}}}{\mathrm{p}_{\mathrm{CO}}}\right)\right]^{2} \\
\mathrm{E}\left(\mathrm{CO}, \mathrm{CO}_{2}\right) / \mathrm{mV}=1458.4-\left[0.447+0.0992 \log \left(\frac{\mathrm{p}_{\mathrm{CO}_{2}}}{\mathrm{p}_{\mathrm{CO}}}\right)\right] \mathrm{T} / \mathrm{K}
\end{gathered}
$$

For $\mathrm{H}_{2} / \mathrm{H}_{2} \mathrm{O}$ and $\mathrm{H}_{2} / \mathrm{H}_{2} \mathrm{O}, \mathrm{CO} / \mathrm{CO}_{2}$ (water gas) similar thermodynamically based equations can be derived [14]. The main application field is the fast measurement of oxygen concentrations in liquid metals and gases, such as flue gases of combustion in steam boilers, in glass and ceramic making industries. By combination of sensor signals with stoichiometric and thermodynamic relations, a complete determination of gas phases under equilibrium conditions is possible [15]. Potentiometric solid electrolyte cells possess the first place among all produced chemical sensors, both with respect to number and the resulting economic effects of their application. The lambda probes for the detection of the oxygen/fuel ratio are also oxygen concentration cells (Figure 2). The signal of a lambda probe (red curve) is low in the case of oxygen excess (lean mixtures, left side, $\lambda>1$ ) and high at an excess of fuel (rich mixtures, $\lambda<1$, right side). Potentiometric cells can be used to investigate flames in-situ in order to determine the border line of the combustion [16]. Oxygen concentration cells can also be constructed with other solid electrolytes (e.g. sodium ion conductors) provided that the ionic transport number is one. But the response time of such sensors is much slower than that of sensors using oxide ion conducting electrolyte. 
Figure 2. Scheme of the voltage characteristics of an idealized hydrocarbon electrode vs. Pt-air reference electrode in hydrocarbon containing mixtures. $\lambda$ denotes the normalized air-to-fuel ratio ( $\lambda>1$ denotes a rich and $\lambda<1$ a lean exhaust gas). Adapted from [12].

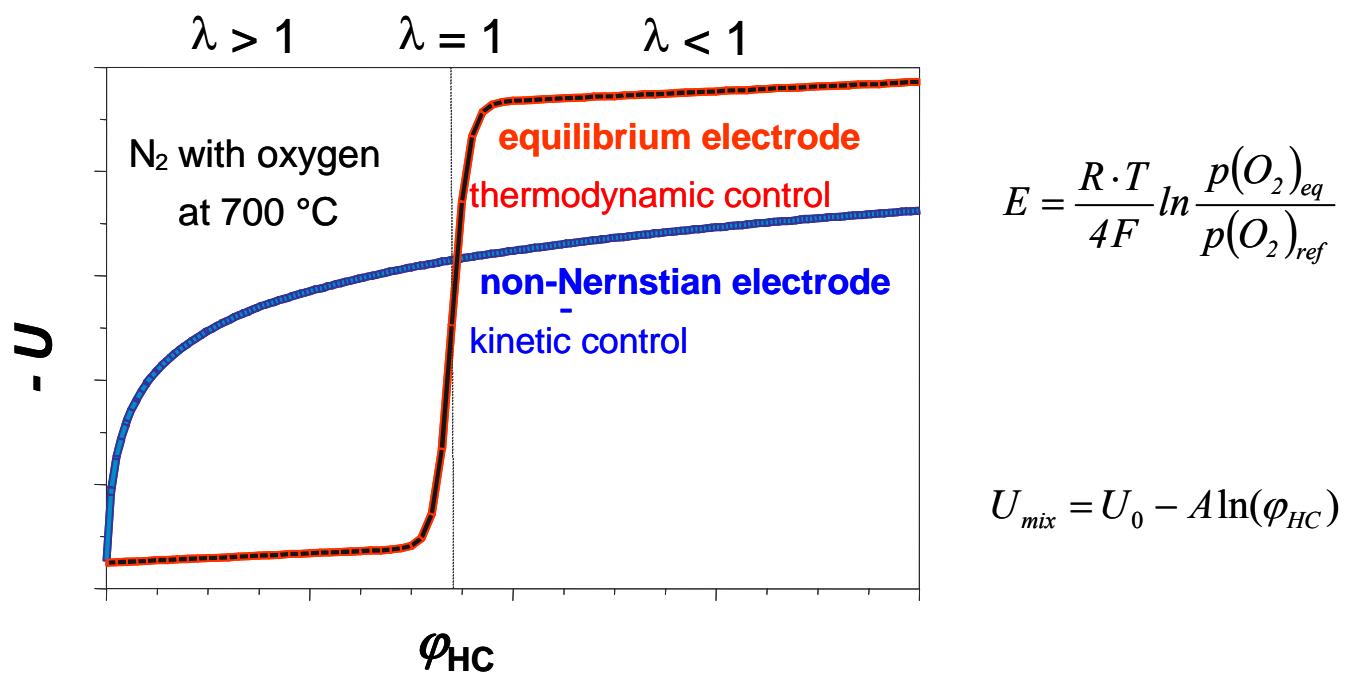

\subsection{Nernst-type Sensors: Novel Materials}

Usually, porous Pt is used as an electrode material. A Pt wire in a close contact to the solid electrolyte as a ligature suffices for high temperatures $\left(>1,100{ }^{\circ} \mathrm{C}\right)$. In the case of $\mathrm{CO} / \mathrm{CO}_{2}$-gas mixtures, deviations from the Nernst equation can be observed when the measured at less than $1,000{ }^{\circ} \mathrm{C}$ (Figure 3). On Ni-electrodes, however, the thermodynamic emf is obtained down to $800{ }^{\circ} \mathrm{C}$.

Figure 3. emf of the gas cell (I) $\mathrm{CO}, \mathrm{CO}_{2}, \mathrm{Pt}|\mathrm{YSZ}| \mathrm{Pt}, \mathrm{CO}, \mathrm{CO}_{2}$ (II). Adapted from [12].

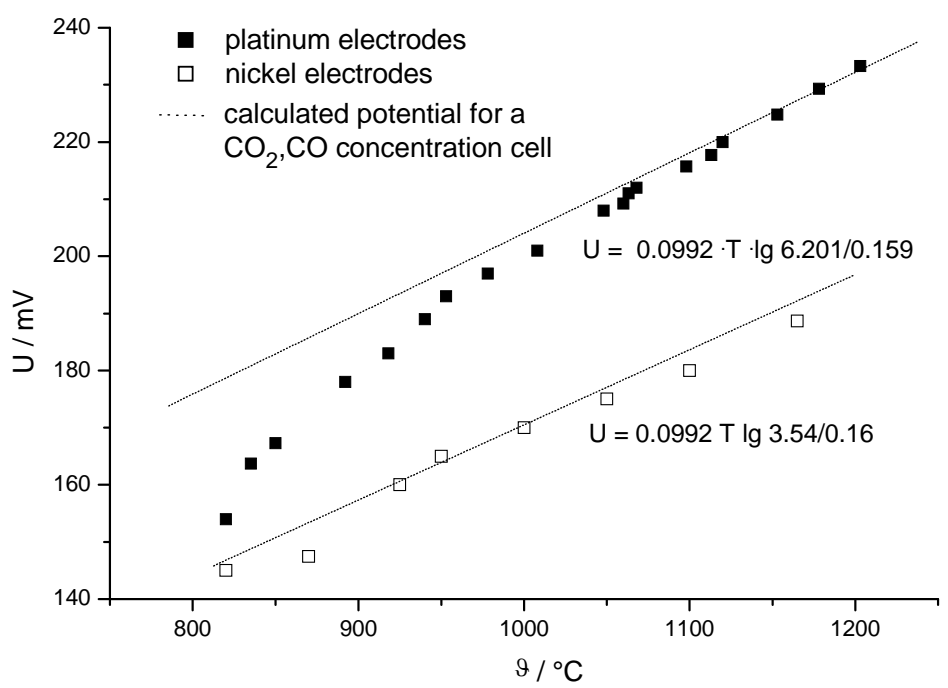

To measure in the equilibrium state at low temperature, very fine $\mathrm{Pt}$, mixed oxides of the perovskite type (e.g. $\mathrm{La}_{0.2} \mathrm{Sr}_{0.8} \mathrm{MnO}_{3}$ ) not only as a sintered layer but also as a powder [17], or Ag can be used. Catalytic non active electrode materials $\left(\mathrm{LaCrO}_{3}\right)$ allow to measure oxygen beside hydrocarbons in a non-equilibrium gas mixtures [18-20]. 
Whilst the application of oxygen sensors in different branches of industry is state of the art [21], Nernstian solid electrolyte sensors for $\mathrm{SO}_{2}$ and $\mathrm{NO}_{x}$ are in an early stage. The activities respecting potentiometric $\mathrm{CO}_{2}$ sensors which are commercially available are summarized more recently [22].

\subsection{Mixed-potential Sensors: Latest Developments}

For a test gas containing hydrocarbons $\mathrm{C}_{\mathrm{m}} \mathrm{H}_{n}$ and an excess of oxygen, the cell voltage follows Equation 4 in the case of an electrochemical equilibrium [23]. The resulting graph is shown in Figure 2, red curve.

$$
E=\frac{R T}{4 F} \ln \frac{\left[p\left(O_{2}\right)-(m+n / 4) p\left(C_{m} H_{n}\right)\right]}{p\left(O_{2}\right)_{\text {ref(air) }}}
$$

The measurement of gas components like hydrocarbons $(\mathrm{HC})$ or nitric oxides $\left(\mathrm{NO}_{\mathrm{x}}\right)$ in nonequilibrated gas phases has become increasingly important. Depending on the electrode material, the gas components do not equilibrate on the measuring electrode at temperatures $<700{ }^{\circ} \mathrm{C}$. Thus, gas components that are not thermodynamically stable are electrochemically active. In $\mathrm{HC}$ and $\mathrm{O}_{2}$ containing gases, at least two electrode reactions can take place: the electrochemical reduction of oxygen and the electrochemical oxidation of hydrocarbons [12]:

$$
\begin{array}{lll}
\text { o } & \text { Oxygen reduction: } & 9 / 2 \mathrm{O}_{2}(\mathrm{~g})+9 \mathrm{~V}_{\mathrm{O}} \bullet+18 \mathrm{e}^{-} \leftrightarrow 9 \mathrm{O}_{\mathrm{O}}^{\mathrm{x}}(\mathrm{YSZ}) \\
\text { o Hydrocarbon reduction: } & \mathrm{C}_{3} \mathrm{H}_{6}(\mathrm{~g})+9 \mathrm{O}_{\mathrm{O}}{ }^{\mathrm{x}}(\mathrm{YSZ}) \rightarrow 3 \mathrm{CO}_{2}(\mathrm{~g})+3 \mathrm{H}_{2} \mathrm{O}(\mathrm{g})+9 \mathrm{~V}_{\mathrm{O}} \cdot \bullet+18 \mathrm{e}^{-} \\
\text {o } & \text { Overall reaction: } & 9 / 2 \mathrm{O}_{2}(\mathrm{~g})+\mathrm{C}_{3} \mathrm{H}_{6}(\mathrm{~g}) \rightarrow 3 \mathrm{CO}_{2}(\mathrm{~g})+3 \mathrm{H}_{2} \mathrm{O}(\mathrm{g})
\end{array}
$$

The measured open circuit voltage does not obey the Nernst equation. Therefore, such electrode behavior is often referred to non-Nernstian electrodes (or mixed potential sensors), see Figure 1b. A mixed potential sensor combines an oxygen electrode as a reference and a second electrode, which shows a low oxygen sensitivity but a high hydrocarbon sensitivity. Both electrodes may be exposed to the analyte gas. Alternatively, the sensor can operate with an oxygen electrode exposed to air as an external reference. According to the theory by Miura [24] based on the Butler-Volmer equation, the cell voltage mainly depends logarithmically on the concentrations (Figure 2, blue curve):

$$
U_{\text {mix }}=U_{0}-\mathrm{A} \ln \left(\varphi_{\mathrm{HC}}\right)
$$

The effect of hydrocarbon sensitivity of Pt electrodes at relatively low temperatures was described as early as 1981 [25]. The mixed potential of such solid electrolyte electrodes is contrary to that of electrodes in aqueous solution very stable and reproducible [26]. The voltage response and the response time depend mainly on the electrode material, its catalytic and electro-catalytic properties. In order to search for suitable materials, the voltage response and the catalytic activity have to be investigated. For screening, it is useful to investigate the deviation from the Nernst equation.

In the last few years, a variety of materials were investigated with respect to their sensitivity and selectivity as mixed potential electrodes. In most cases, the increasing catalytic conversion of combustibles prevents the appearance of mixed potentials above $800{ }^{\circ} \mathrm{C}$. On the other hand, Wang et al. [27] have found a high sensitivity for $\mathrm{NO}_{\mathrm{x}}$ using $\mathrm{Rh}-\mathrm{NiO}$ electrodes, even at $800{ }^{\circ} \mathrm{C}$. One of the 
most intensively discussed and investigated questions concerning non-Nernstian solid electrolyte sensors is that of the electrode process with most relevance for the signal [28,29]. Besides potentiometric measurements, a variety of other investigation methods like amperometric, impedimetric [30-32], catalytic [26] and response measurements were utilized to answer this key question. It seems that mixed potential theory as well as chemisorption processes, connected with changes in the Fermi level of the electrode material [33] can contribute to the sensing mechanism. The response time $\left(450{ }^{\circ} \mathrm{C} \ldots 750{ }^{\circ} \mathrm{C}\right)$ depends on the kind of gas [34] and is comparable with that of an $\mathrm{O}_{2}$, $\mathrm{Pt} / \mathrm{YSZ}$-electrodes as shown in Figure 4. The shape of different response curves suggests that different time steps depending on gas composition are involved at the same electrode.

Figure 4. Normalized response of a miniaturized planar gas sensor at $650{ }^{\circ} \mathrm{C}$. Cell symbol: $\mathrm{Au}, \mathrm{NiO} / \mathrm{YSZ} / \mathrm{Pt}$ with $\mathrm{Au}, \mathrm{NiO}$ composite mixed potential electrode (YSZ, yttria stabilized zirconia) Reprinted from [34] with permission from Elsevier.

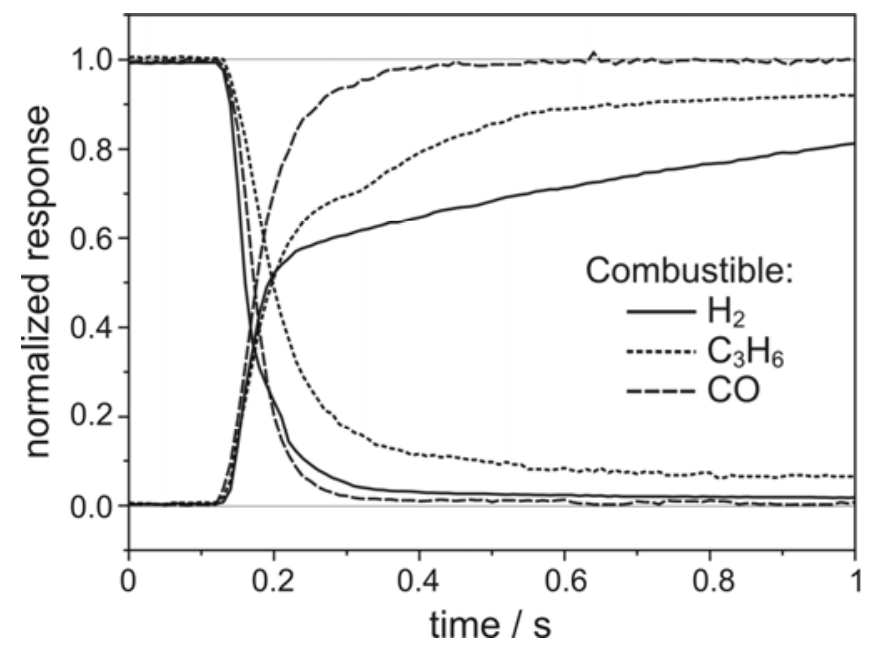

Up to now, many questions concerning the complex behavior of electrode materials in different gases are still open. Therefore, the trial-and-error search for new electrode materials is still state of the art for this type of gas sensors. A lot of different electrode materials are under investigation especially in Miura's group [35-37]. Nevertheless, investigations of the Guth group show [26] that the sensitivity of different $\mathrm{Au}$ oxide composite electrode materials (e.g. $\mathrm{Au}, \mathrm{Nb}_{2} \mathrm{O}_{5}$ ) for one combustible may be correlated with the catalytic activity of these electrode materials for oxidizing this combustible. In the case of mixed oxide electrodes $\left(\mathrm{La}_{0.6} \mathrm{Ca}_{0.4} \mathrm{Mn}_{1-\mathrm{x}} \mathrm{Me}_{\mathrm{x}} \mathrm{O}_{3} \mathrm{Me}=\mathrm{Co}\right.$, Ni), it seems to be a correlation between the voltage response and the kind of conductivity (p- or n-type) [32]. Meanwhile, mixed potential sensors are commercially available to detect the breakthrough of hydrocarbons in air cleaning filters [38] or to monitor the metabolism in biochemistry [39]. 


\subsection{Direct Thermoelectric Sensors: a Novel Potentiometric Principle}

A novel potentiometric principle has been investigated recently for both equilibrium oxygen sensing and detection of combustibles: the direct thermoelectric principle [40,41]. In resistive gas sensors that are based on semiconducting oxide films, the film resistivity changes due to redox reactions of the analyte with the sensor material (confer Section 3). These resistivity changes are either governed by surface effects at temperatures below $500{ }^{\circ} \mathrm{C}$, like in n-type semiconducting $\mathrm{SnO}_{2}$ [2] or by volume effects occurring mostly above $700{ }^{\circ} \mathrm{C}$. In all cases, the electronic charge carrier density (electrons, holes) changes when the material is exposed to the analyte. A major disadvantage of these resistive devices is the dependency of the measurand "sensor resistance" on the film geometry and morphology. For that reason, the measurand is also affected by cracks in the film, by abrasion of the film, or by sintering of the film during operation. Whereas the geometry dependency is crucial for reproducible manufacturing, the latter issues strongly affect long-term stability. In a a direct thermoelectric sensor device, these problems are overcome [40,41]. Here, the Seebeck coefficient $\varepsilon$ of the material is directly measured. In principle, $\varepsilon$ describes the position of the Fermi-level in the band scheme and hence, it is correlated with the concentration of the electronic charge carriers in semiconducting materials. For example, in n-type semiconducting oxides, $\varepsilon$ is related with the electron density $n$ by Equation 6 [42]:

$$
\varepsilon=-\frac{k}{e} \cdot\left(\ln \frac{N_{C}}{n}+A_{\mathrm{e}}\right)
$$

In Equation 6, $k$ is the Boltzmann constant, $e$ the electron charge, $N_{\mathrm{C}}$ the effective density of states in the conduction band, and $A_{\mathrm{e}}$ is a scattering mechanism-dependent transport coefficient for electrons. Unlike the conductivity, $\varepsilon$ is independent from the geometry of the gas sensitive material. Despite the relationship between Seebeck coefficient and the conductivity of metal oxides had been evaluated very early by Jonker [43], only scattered works are known implementing this principle as a sensor device, e.g. [44-46].

A basic sensor setup comprises a heater to bring the whole device to operation temperature, insulating layers, and a heater providing a modulated temperature gradient $\Delta T$ over the gas sensitive film. The measured thermovoltage of the material, $V_{\mathrm{S}}$, is a function of the Seebeck coefficient of the film material $\varepsilon$ and of the applied temperature difference $\Delta T$ :

$$
V_{\mathrm{S}}=\left(\varepsilon_{\text {lead }}-\varepsilon\right) \Delta T
$$

$V_{\mathrm{S}}$ includes the usually known or at least constant thermovoltage of the leads $V_{\text {lead }}=\varepsilon_{\text {lead }} \Delta T$. Knowing $V_{\mathrm{S}}$ and $\Delta T$, the Seebeck coefficient of the sample $\varepsilon$ can be derived. Typically, $\Delta T$ is modulated periodically and $V_{\mathrm{S}}(\Delta T)$ is measured. $\varepsilon$ is deduced from the slope of all data points in the $V_{\mathrm{S}}$ vs $\Delta T$-plot by applying Equation 7 .

On the one hand, this principle is suitable for oxygen sensors. Here, the electron and hole densities in the equilibrium are determined by the oxygen partial pressure, $\mathrm{pO}_{2}$, of the surrounding atmosphere. As expected from defect chemistry in the pure n-type and p-type regime, only a slight dependency of $\varepsilon$ on $\mathrm{pO}_{2}$ can be found $[47,48]$. Suitable materials are almost all semiconducting oxides, if their oxygen diffusion coefficient is high enough for a fast sensor response, and if a $\mathrm{pO}_{2}$-variation affects 
significantly the mobile electronic charge concentrations. For instance, electrode materials for SOFC might not be suitable for that purpose, since their charge carrier density does not change markedly with $\mathrm{pO}_{2}$. Examples for realized sensor devices to measure in the pure p-type regime are shown in [40] using $\mathrm{SrTi}_{1-x} \mathrm{Fe}_{x} \mathrm{O}_{3-\delta}$, an excellent material for resistive oxygen sensing [49] or hydrocarbon sensing at lower temperatures [50]. However, slopes of only $52 \mu \mathrm{VK}^{-1}$ per decade $\mathrm{pO}_{2}$ could have been achieved. Much more sensitive devices can be obtained, if one shifts the $\mathrm{S}$-shaped $\varepsilon\left(p O_{2}\right)$-curve by appropriate doping into the intrinsic regime, where donors and acceptors compensate mainly itself in the $\mathrm{pO}_{2^{-}}$ range of interest. Then, a slight increase in the $\mathrm{pO}_{2}$ is sufficient to shift $\varepsilon$ from negative values to positive ones. Rettig succeeded in preparing sensors with an intrinsic semiconductor showing almost linear slope in the $\varepsilon\left(p O_{2}\right)$-plot of $186 \mu \mathrm{VK}^{-1}$ per decade $p O_{2}$ [51].

On the other hand, the direct thermoelectric principle has been successfully tested for the detection of reducing gases like hydrocarbons using doped $\mathrm{SnO}_{2}$ [45,52]. The huge advantage of the direct thermoelectric gas sensors is impressively demonstrated in Figure 5 [52]. Both the Seebeck-coefficient and the resistance of a gas sensitive $\mathrm{SnO}_{2}$-film were measured under different propane concentrations. A part of the film was deliberately milled out. The sensor was measured again under the same conditions. Obviously, the resistance of the gas sensitive film increased by about $100 \%$ after milling out a part of the gas sensitive film (sensor reading $28 \mathrm{ppm}$ instead of the true value of $100 \mathrm{ppm}$ ). The Seebeck coefficient, however, decreased only by about $5 \%$; i.e. the sensor reading is 80 ppm propane instead of the true value of $100 \mathrm{ppm}$.

Figure 5. Seebeck coefficient (a) and resistance (b) of a $\mathrm{SnO}_{2}$ gas sensor before and after milling out a big part of the gas sensitive film (from [52]). With permission from IEEE (C) 2007 IEEE).
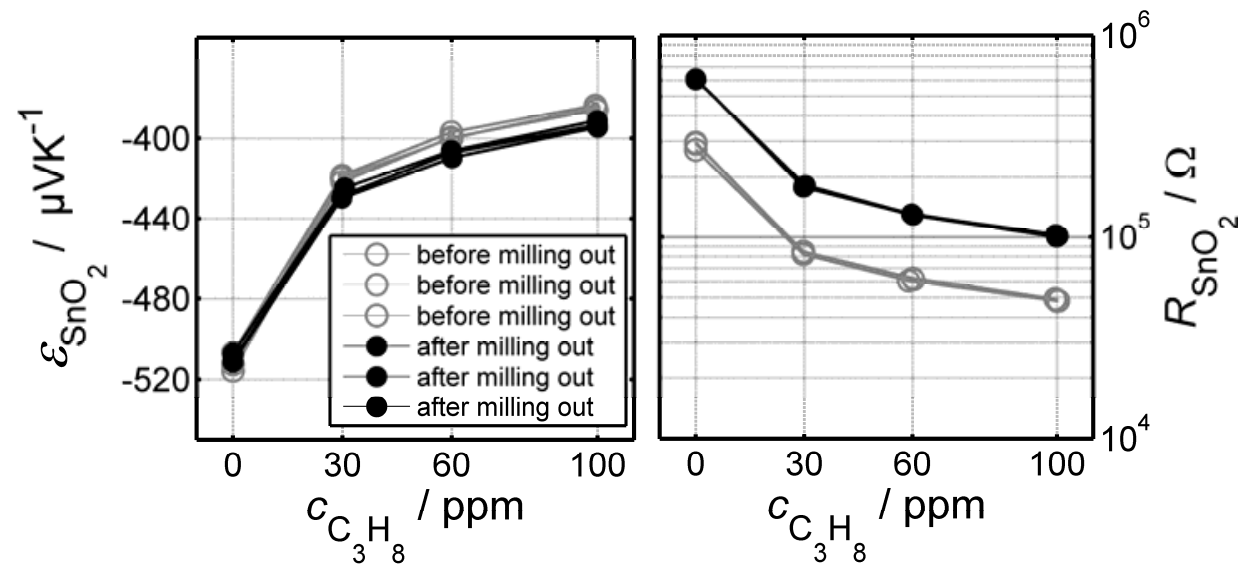

The effect of the morphology and the influence of dopants was evaluated numerically [51]. Utilizing fine-grained intrinsic or slightly donor-doped materials would be a good choice, since in that case the sensitivity of the thermoelectric gas sensor reaches a high value and the sensor resistance is almost not affected by the analyte concentration. A direct thermoelectric sensor made of such a material would have the benefit that by measuring both the thermopower and the resistance, the resistance value can serve as a temperature signal or if the temperature is known, it could indicate sensor poisoning. 
Not only electronic conductors can be employed as materials for direct thermoelectric gas sensors. It has been shown several years ago that the total thermopower $\varepsilon$ of an electrochemical cell with $\mathrm{Pt}$ electrodes that are separated by an ionic oxygen conductor can be written as [53]:

$$
\varepsilon=S(T)-\frac{k}{4 e} \cdot \ln \left(p_{O_{2}}\right)-\frac{Q_{O^{2-}}^{\bullet}}{2 e T}-\varepsilon_{P t}
$$

Herein, $S(T)$ is the entropy term, $Q_{\mathrm{O} 2-}$ is the heat of transport of the oxygen ions, and $\varepsilon_{\mathrm{Pt}}$ the thermopower of the Pt electrodes. In a first order approximation, these three terms can be regarded as constant and a theoretical sensitivity $s$ of the thermoelectric cell can be derived:

$$
s=\frac{d \varepsilon}{d \log \left(p_{\mathrm{O}_{2}}\right)}=-\frac{k}{4 e} \ln 10
$$

This amounts to a slope of $s \approx-50 \mu \mathrm{VK}^{-1}$ per decade $\mathrm{pO}_{2}$ and is in the same order of magnitude as for semiconductor materials.

The first implementation of such a sensor device is reported in [54]. 8 mol\% $\mathrm{Y}_{2} \mathrm{O}_{3}$ stabilized zirconia, YSZ, was used for the membrane material. From the results in Figure 6 it is obvious that the expected sensitivity is reached. Astonishingly, almost no temperature dependency of $\varepsilon$ occurs, indicating that the three $\mathrm{pO}_{2}$-indpendent terms have either a negligible temperature dependency or their temperature dependency compensates each other. Additionally, no cross sensitivities towards $\mathrm{NO}, \mathrm{H}_{2}, \mathrm{H}_{2} \mathrm{O}, \mathrm{CO}, \mathrm{CO}_{2}$ and $\mathrm{HC}$ are observed.

Figure 6. Sensor signal vs oxygen partial pressures for three different temperatures. Please note the very low temperature dependency. Figure adapted from [54]. Reprinted from [54] with permission from Elsevier.

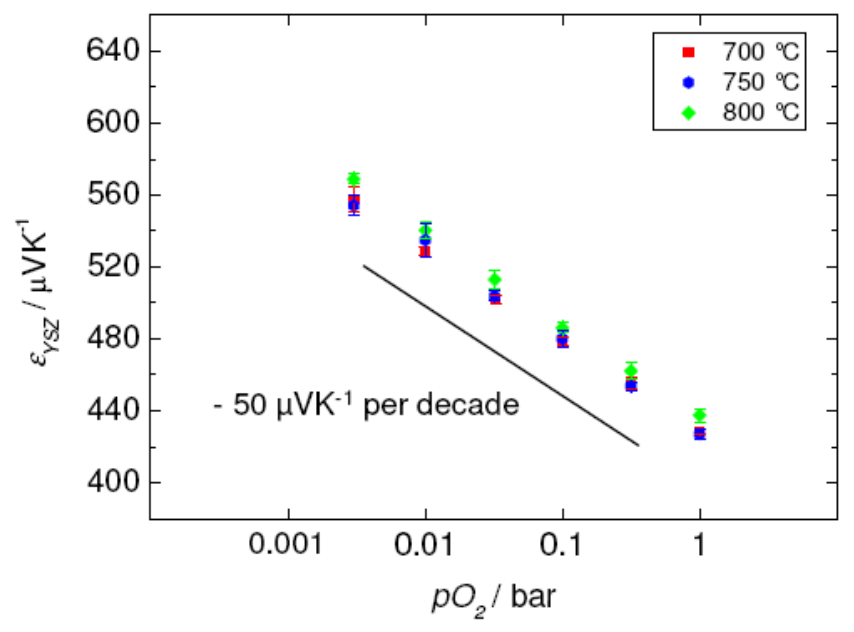

These results deserve a comparison with the conventional potentiometric lambda-probe as described in [10] or [4]. The conventional lambda-probe has the clear advantage of a sensitivity of about $50 \mathrm{mV}$ per decade $\mathrm{pO}_{2}$ when operated at $735{ }^{\circ} \mathrm{C}$. Even if one applies a $\Delta T$ of $50{ }^{\circ} \mathrm{C}$ over the direct thermoelectric gas sensor, a sensitivity of only $2.5 \mathrm{mV}$ per decade $\mathrm{pO}_{2}$ occurs. This disadvantage competes with the simpler sensor setup. No reference atmosphere is required and very tiny samples with a fast light-off time requiring only very low power for operation seem feasible. Nevertheless, it is 
to emphasize that the direct thermoelectric gas sensor principle is in an early research state far away from market ripeness.

\section{Amperometric Sensors}

In amperometric gas sensing devices, the reaction of an analyte at an electrode generates a current which is then measured commonly at a fixed applied potential. A linear relationship between current and concentration is observed. Reference [55] gives a detailed review on amperometric gas sensor devices, encompassing solid polymer electrolyte (SPE) sensors based on Nafion as well as on sensor cells based on doped zirconia, i.e., two-chamber devices for the simultaneous detection of $\mathrm{NO}$ and $\mathrm{O}_{2}$ and oxygen pumping cells.

To further reduce cross-interference of other analytes on the sensor signal, the use of highly selective biological components (e.g., enzymes or antigene/antibody pairs) has received increased attention [56]. Due to their specific reaction sites following the "lock and key" model, these biocomponents only interact with particular analytes (also called substrates). Hence, they are ideal candidates for the preparation of selective electrochemical sensing cells. The cell output, an electrical current, can be linked to the analyte concentration.

Due to stability issues of the biological agents, most of the corresponding amperometric devices are applied exclusively in the liquid phase for the detection of solutes. One example is the well-known glucose sensor based on glucose oxidase for monitoring diabetes. More novel biosensor concepts, however, aim at the direct electrochemical detection in the gas phase. Mitsubayashi et al. were the first to report gas-phase biosensors for various analytes ranging from ethanol and formaldehyde to trimethylamine, methylmercaptan, and acetaldehyde, e.g. Refs. [57] or [58]. In this case, the sensitive enzyme was immobilized on a Pt-coated PTFE membrane.

In Germany, similar gas-biosensors for formaldehyde, ethanol, and phenol sensing were studied at the University of Bayreuth. For each of the analytes, an appropriate enzyme/gas-diffusion electrode combination was investigated, and sub-ppm level detection was successfully demonstrated [59,60]. The sensor devices consisted of a liquid compartment containing the enzyme and further organic components in a buffered electrolyte system. From the gaseous environment to be monitored, gases diffuse into the liquid reaction volume via a PTFE membrane. In addition, the authors showed that despite the high intrinsic specificity of the enzyme itself, all components of the complex biosensor system need to be taken into account when studying cross-interferences [61]. In the case of the formaldehyde sensor, for example, a low interference of $\mathrm{CO}_{2}$ and $\mathrm{NO}$ on the sensor signal was observed. This could be linked to either mediator or electrode interactions, and could be reduced by a careful choice of these components.

In a continued study, the initial sensor setup was miniaturized by applying laser micromachining and low-temperature co-fired ceramics (LTCC) technology [62]. The organic diffusion membrane was replaced by a porous metalized ceramic electrode. A reusable hybrid sensor platform was achieved.

\section{Conductometric Sensors}

Metal oxide semiconducting sensors of the resistive or conductometric type have been thoroughly investigated for decades. In the 1950s and 1960s, various research groups reported that some metal 
oxides change their conductivity significantly when exposed to reducing gases at high temperatures around $400{ }^{\circ} \mathrm{C}$ [63-65]. Soon after this discovery, first sensor devices based on tin oxide were commercialized, and the research was expanded to other metal oxide candidates. Numerous reviews on gas sensor devices of the so-called Taguchi type are available [66-69].

The novel trends reviewed in the present section start with n-type and p-type semiconductors. Main focus of the recent research work in this field is to understand the sensing mechanisms in a qualitative and quantitative way with respect to further sensor improvements. Recently, research on zeolites for gas sensor application came up due to the excellent selectivity that can be obtained as a result of the framework structure of these aluminosilicates.

The German key gas sensor labs also work on novel deposition techniques, which may supplement the common thick and thin film methods.

\subsection{Novel Trends in n-type Semiconducting Sensors}

\subsubsection{Operando Studies}

Recognizing that one of the major problem encountered by the R\&D in the field of gas sensors is the lack of experimental information (phenomenological and spectroscopic) that is gained under the same conditions in which the sensors are operated and on samples that are similar to real sensors, the group at the University of Tübingen established a battery of electrical and spectroscopic techniques able to do exactly that. For the semiconducting metal oxides based ones, an example of the used samples/sensors is presented in Figure 7. The sensing layers are screen-printed or drop coated porous thick films of polycrystalline metal oxides. The substrates are made of alumina provided with thick film Pt electrodes and heaters, which is also how most commercial sensors are constructed. In the experimental setups, sensors are characterized in normal working conditions (normal pressure - 1 bar; dynamic system for dosing of the gaseous composition of the sensor ambient - r.h. between 0 and $90 \%$, target gases concentration between few ppb and $100 \%$, total flow between 10 and $1,000 \mathrm{ml} / \mathrm{min}$; adjustment of sensor temperatures between r.t. - $500{ }^{\circ} \mathrm{C}$; “operando" techniques), see Error! Reference source not found.7.

Figure 7. Typical samples used in the operando studies.
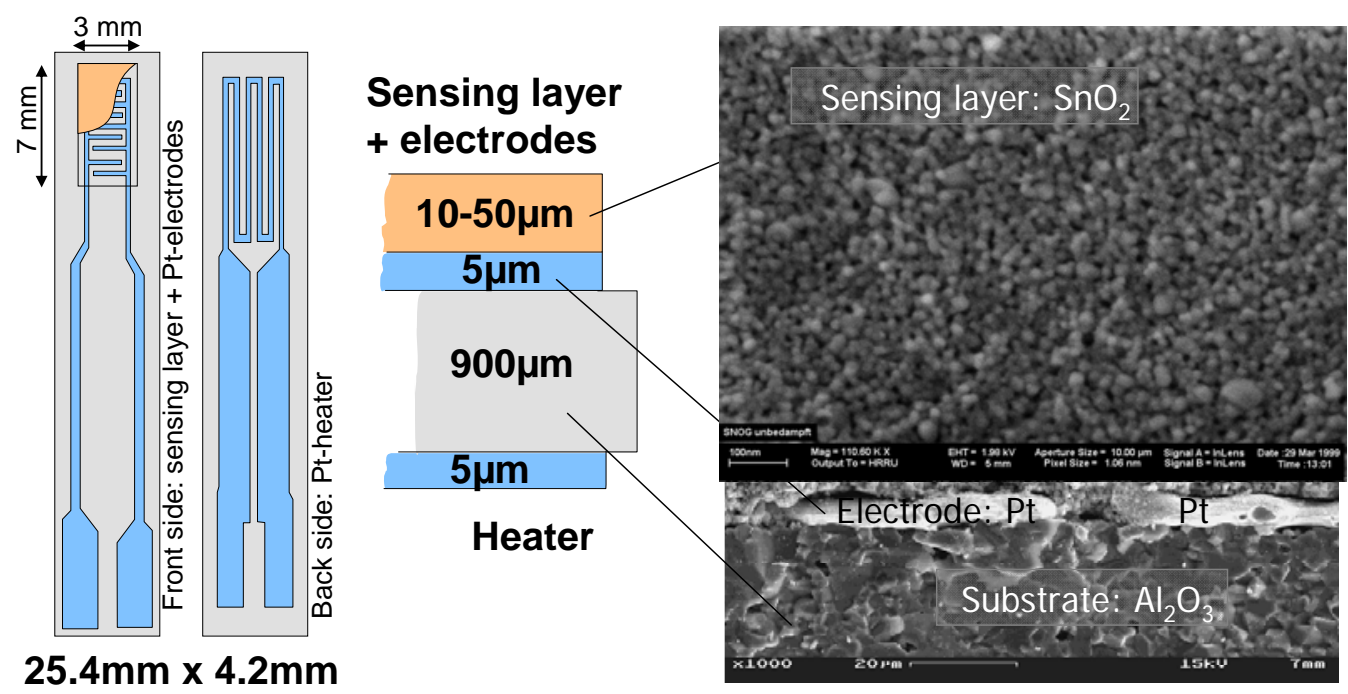
An overview is provided in [70]. The available measurement techniques are (see Figure 8):

o DC resistance measurements give information about changes in the concentration of free charge carriers induced by surface reactions.

o AC impedance spectroscopy allows for identifying charge depleted regions such as surface space charge layers or metal-metal oxide contacts and of the nature of free charge carriers (ions or electrons). The changes induced by gas reactions allow following the way in which charge transfer processes effect the free charge carrier transport and the dielectric properties.

o Hall effect measurements give information about the various contribution to the conductance changes (of mobility and/or free charge carrier concentration) when combined with the DC resistance measurements. They provide insights that help to model the conduction processes in the sensing layer.

o Work function changes are measured by the Kelvin method (details see Section 4). They help to evaluate the impact of surface reactions (charge transfer processes between gases and metal oxides). In combination with conductance measurements localized chemisorption and ionosorption can be discriminated.

o On-line gas analysis of the composition of the sensor ambient atmosphere allows determining the end products of solid-gas interaction and gives insight about the possible reaction paths.

o Diffuse Reflection Infrared Fourier Transformed Spectroscopy (DRIFTS) measurements are allowing for the identification of the adsorbed surface species involved in the gas solid reaction. It is one of the few spectroscopic techniques possible to be applied in-operando and its input is essential for the identification of reaction mechanisms.

Figure 8. Operando methodology.

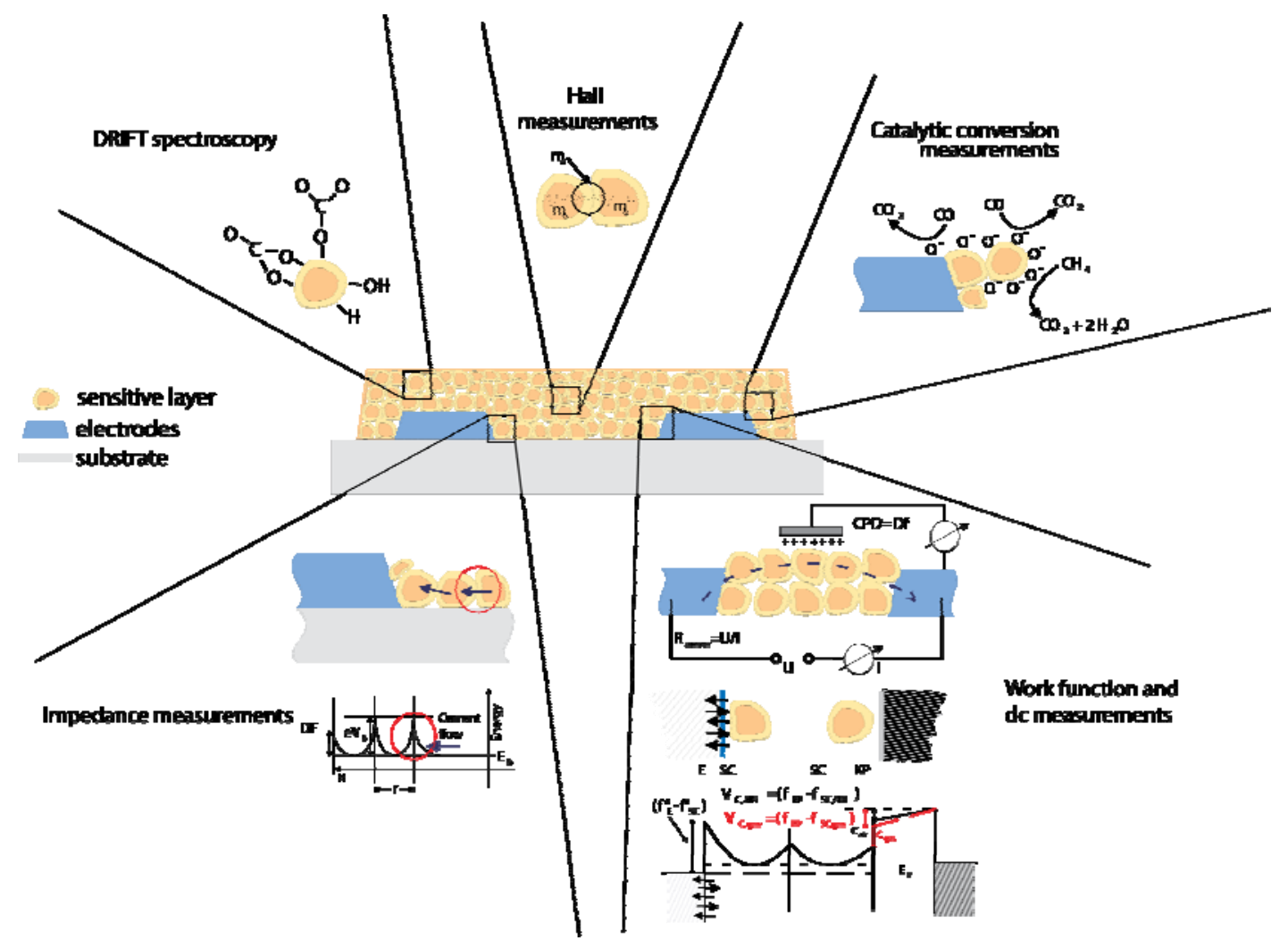




\section{Overview of operando results}

The full battery of techniques was applied to the understanding of the influence of water vapor on the $\mathrm{CO}$ sensing mechanism in Pd-doped $\mathrm{SnO}_{2}$ [68] in combination with the modeling of the transduction processes in metal oxide layers [69]. This model system was chosen due to its relevance for application and due to the fact that the effects recorded with this material were significantly out of noise. By monitoring the catalytic conversion of $\mathrm{CO}$ to $\mathrm{CO}_{2}$ the adsorption/reaction of $\mathrm{CO}$ to $\mathrm{CO}_{2}$ at the surface of $\mathrm{Pd}$-doped $\mathrm{SnO}_{2}$ was found to be a linear process. This indicates that the nonlinear sensor response is related to the transduction mechanism [71]. Also it was revealed that differently bound water and specific surface $\mathrm{OH}$-groups react with $\mathrm{CO}$. The so formed surface carbonate ions dissociate due to acidic intermediate products [72,73]. The DRIFTS results permitted to identify the generation of hydrated protons as being responsible for the increasing sensor conductance. This was crucial since the results from DC conductance, from AC impedance spectroscopy, and from work function measurements could not point at the responsible surface species. An especially important insight revealed by AC impedance spectroscopy was the identification of differently active regions in the sensing layer suggesting a catalytic effect of the Pt electrodes.

Differently prepared $\mathrm{SnO}_{2}$ materials (Flame Spray Pyrolysis powders [74]) were studied by a combination of work function and DC conductance measurements. The study of the interaction with oxygen indicated that for low oxygen concentrations at high temperatures $\left(400{ }^{\circ} \mathrm{C}\right)$ the ionic oxygen species dominate whereas at lower temperatures $\left(200^{\circ} \mathrm{C}\right)$ a dipolar interaction of molecular oxygen with $\mathrm{SnO}_{2}$ has to be taken into consideration. This result questions the widely accepted mechanism for the interaction between atmospheric oxygen and $\mathrm{SnO}_{2}$, which takes into consideration only ionic adsorbed oxygen species. It can be combined with simultaneous DRIFTS and DC conductance measurements [75]. On hydrothermally prepared $\mathrm{SnO}_{2}$ a significant interaction between adsorbed oxygen ions and water vapor was observed which leads to the formation of terminal hydroxyl groups on tin dioxide surface. This observation is an evidence of water-oxygen interaction and could explain the observed change of electronic affinity during oxygen exposure by relating it to the build-up of new hydroxyl groups.

Figure 9 shows results obtained for differently prepared undoped $\mathrm{SnO}_{2}$ materials (in fact, no surface sensitizers like Pd or Pt were added to the materials). The presented spectral region corresponds to the hydroxyl groups. It important to notice that, even if the surfaces of the different sensors are very different from the point of view of adsorbed species, the effect of oxygen exposure is very specific in all three cases. Obviously, the observed phenomenon has a general character for undoped $\mathrm{SnO}_{2}$. The interaction between water and oxygen explains also why the sensor effect for reducing gases in undoped tin oxide decreases in the presence of humidity.

Besides oxygen, water vapor and $\mathrm{CO}$ interaction with $\mathrm{SnO}_{2}$, hydrocarbon surface reactions were also investigated by DC conductance, catalytic conversion and DRIFTS measurements [77,78]. In all cases, the resulting products of the hydrocarbons interaction are $\mathrm{CO}_{2}$ and $\mathrm{H}_{2} \mathrm{O}$, indicating a complete conversion. During propane interaction with $\mathrm{SnO}_{2}$, the surface ionic species plays a crucial role. The results indicate that the $\mathrm{C}_{3} \mathrm{H}_{8}$ dehydrogenation is initiated by hydrogen abstraction over a surface acid-base lattice pair site and leads to the formation of $\mathrm{C}_{3} \mathrm{H}_{7}$. Its further transformation is caused by reaction with the adsorbed oxygen species. The main intermediate surface species during the 
consecutive conversion of propane are ionic carbonates and carboxylates. Additional work function measurements confirm that the intermediates are ionic, i.e., they really stem from a reaction involving adsorbed oxygen species and not surface lattice oxygen.

Figure 9. Single channel DRIFT spectra of different tin dioxide sensors exposed to oxygen at constant humidity level (3 ppm) 70 ppm O were screen-printed starting from pre-processed powders realized either by Flame Spray Pyrolysis [76] (Sensor 3) or by sol-gel (Sensor 1 and 2; with different calcinations temperatures, $500{ }^{\circ} \mathrm{C}$ and $700{ }^{\circ} \mathrm{C}$, respectively).

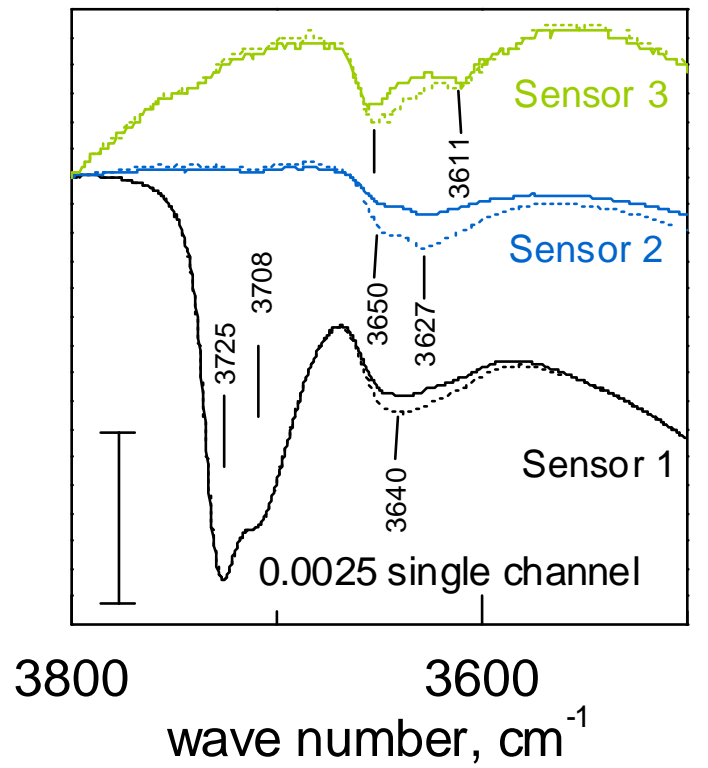

Other interesting findings deal with the effect of the electrode nature on the gas sensing mechanism $[79,80]$. It is known that, e.g. Pt or Au electrodes, have an effect on the sensor response. Many speculations on the reasons exist. By using DC conductance and DRIFTS measurements it was demonstrated that the different nature of the electrodes changes the chemistry involved in CO sensing. Different distribution between carbonates and carboxylates, which are the reaction intermediates when $\mathrm{CO}$ is converted to $\mathrm{CO}_{2}$, were identified.

Other materials were investigated besides $\mathrm{SnO}_{2}\left(\mathrm{In}_{2} \mathrm{O}_{3}, \mathrm{WO}_{3}, \mathrm{TiO}_{2}\right.$ and $\left.\mathrm{Cr}_{2} \mathrm{O}_{3}\right)$. Very interesting is the identification of the origin of the transition in the conduction type of $\alpha-\mathrm{Fe}_{2} \mathrm{O}_{3}$ from $n$ - to $p$-type due to the presence of oxygen. This $n$ - to $p$-type transition has an electronic origin [81]. If the resistance goes through a maximum when exposed to reducing gases, the work function decreases (decrease of the energy band bending). This rules out a change in the surface chemistry associated with the reaction with the reducing gases. The adsorption of oxygen leads to a strong depletion of electrons near the surface (upwards energy bands bending) and thus to the formation of a surface layer in which the conduction switches from $n$ to $p$-type (inversion layer). This means that already the adsorbed oxygen traps electrons from the valence band, and holes as free charge carriers can appear. As long as hole conduction dominates, the resistance increases when the sensor is exposed to reducing gases, because the decrease of the hole concentration is not compensated by an increasing electron concentration. When the concentration of the reducing gases is high enough, the $n$-type conduction is restored and an increase of the reducing gases concentration determines a decrease of the sensor resistance. The 
overall impact of reducing gases is an initial resistance increase up to a maximum resistance value (corresponding to the intrinsic conduction regime) and a subsequent resistance decrease. This gets reversed by adding strong reducing gases, because the latter react with ionosorbed oxygen under release of electrons into the conduction band.

Recently, it was even investigated, how surface reactions-induced electrical changes are affecting the sensor signals of thick porous layers of p-type $\mathrm{Cr}_{2} \mathrm{O}_{3}$, by using simultaneous DC, work function changes (Kelvin probe method), and AC impedance spectroscopy measurements [82]. Based on them, a conduction model, which qualitatively explains the experimental data, was developed. It explains the large mismatch between the work function changes and the resistance change.

\subsubsection{One Dimensional Materials}

The group of Mathur at the University of Cologne was very active in the last period in the field of anisotropic metal oxide nanostructures, especially $\mathrm{SnO}_{2}$, see e.g. In [83] the authors examined a general strategy for the fabrication and characterization of portable nanowires-based devices while in [84] they tried to take on the basic interaction between oxygen and the tin oxide nanowires. The synthesis of the nanowires is realized by catalyst supported chemical vapor deposition and their contacts are realized by using lithographic processes. The main idea is that by studying individual nanowires one can get a better insight in the sensing because the nanowires are a very good surface controlled single crystal and one avoids the complications of complex interconnections present in the classical thick or thin film approaches.

An alternative approach for the synthesis of nanowires was undertaken by Polleux et al. [85], namely a soft chemistry route. The resulting materials are crystalline $\mathrm{WO}_{3}$ nanowires self assembled into bundles at low temperature, which were drop coated onto alumina substrates. The resulting sensors were proven to show high sensitivity towards $\mathrm{NO}_{2}$.

\subsection{P-type Materials}

As discussed in the previous subsection, the $n$-type conducting oxide ceramics, in particular doped or coated $\mathrm{SnO}_{2}$, have received much attention in conductometric gas sensing. Their $p$-type conducting counterparts are scarcely discussed, although early publications already state the potential advantages of $p$-type oxide ceramics due to their stability [86,87] and their higher catalytic activity for oxidation reactions [88]. Some exceptions include the commercially available ammonia gas sensors, $\mathrm{Cr}_{2-\mathrm{x}} \mathrm{Ti}_{\mathrm{x}} \mathrm{O}_{3}$ $[89,90]$, and $\mathrm{NO}_{\mathrm{x}}$ sensors based on perovskite rare-earth metal oxides of the $\mathrm{LnFeO}_{3}$ family, where $\mathrm{Ln}$ is $\mathrm{La}, \mathrm{Nd}, \mathrm{Sm}, \mathrm{Gd}$ and Dy [91].

In the 1990s, Moos et al. studied the sensor characteristics of $\operatorname{SrTi}_{1-x} \mathrm{Fe}_{x} \mathrm{O}_{3-\delta}$, a $p$-type conducting semiconductor formulation with the perovskite structure $[49,92]$. Initially, this material was introduced for conductometric oxygen sensing at temperatures between $700{ }^{\circ} \mathrm{C}$ and $900{ }^{\circ} \mathrm{C}$. Compared to the conventional potentiometric oxygen probes based on yttria-doped $\mathrm{ZrO}_{2}$ (confer Section 1), such conductometric sensors present a simpler set-up and are thus an inexpensive alternative when manufactured in thick-film technology [92]. As an additional advantage, a temperature independent resistance over this temperature range was reported for the $\mathrm{SrTi}_{0.65} \mathrm{Fe}_{0.35} \mathrm{O}_{3-\delta}$-composition in particular $[49,93]$. Detailed studies were aimed at resolving the observed proneness of the devices to sulfur 
poisoning [94,95]. In other work by German researchers, $p$-type members of the system $\mathrm{La}_{2} \mathrm{CuO}_{4}: \mathrm{LaFeO}_{3}$ were identified as alternative candidates for temperature independent oxygen sensors [96-98] and a model of the sensor behavior was proposed [99].

In addition to the promising oxygen sensor characteristics of $\mathrm{SrTi}_{0.65} \mathrm{Fe}_{0.35} \mathrm{O}_{3-\delta}$, the members of the $\mathrm{SrTi}_{1-x} \mathrm{Fe}_{x} \mathrm{O}_{3-\delta}$ perovskite family with $x \leq 0.2$ have been reported as promising materials for hydrocarbon sensing in the temperature range from $350{ }^{\circ} \mathrm{C}$ to $450{ }^{\circ} \mathrm{C}[100,101]$. The initially studied screen-printed sensor elements presented a fast, stable, and reproducible hydrocarbon response. In order to improve sensor functionality and to identify corresponding key parameters, the material characteristics were optimized with respect to operating temperature, iron content, film thickness, and particle size. By enhancing the surface-to-volume ratio of the devices, which was achieved either by the use of nano-scaled sol-precipitated precursors [50] or by electrospinning techniques (cf. Section 3.4) [102], the selectivity towards propene was increased. To reflect the difference between this $p$-type material and the commonly used $n$-type semiconductors of the Taguchi type (cf. Section 3.1), a novel sensor model was proposed to explain the sensor effect in a quantitative way [103]. For $n$-type sensor models, the redox process that is responsible for the sensor response to reducing gases is confined to the sensor surface. According to observations reported for $p$-type semiconducting oxidation catalysts, however, it is very likely that lattice oxygen is exchanged when they are exposed to reducing gases [104]. Hence, a reduction process affecting the entire bulk was assumed to govern gas sensitivity of $\mathrm{SrTi}_{1-\mathrm{x}} \mathrm{Fe}_{\mathrm{x}} \mathrm{O}_{3-\delta}$ films in the refined $p$-type model. Figure 10 illustrates the good agreement between the model results (lines) and the experimental data (symbols) [103]. Here, the conductometric sensor response of two sensors with a different microstructure towards a variety of gases was considered.

Figure 10. Comparison between model (lines) and experimental results (symbols). (a) Coarse-grained powder, $\mu \mathrm{m}$ scale. (b) Fine sol-precipitated powder, nm-scale (from [103]). Reproduced by permission of the PCCP Owner Societies.
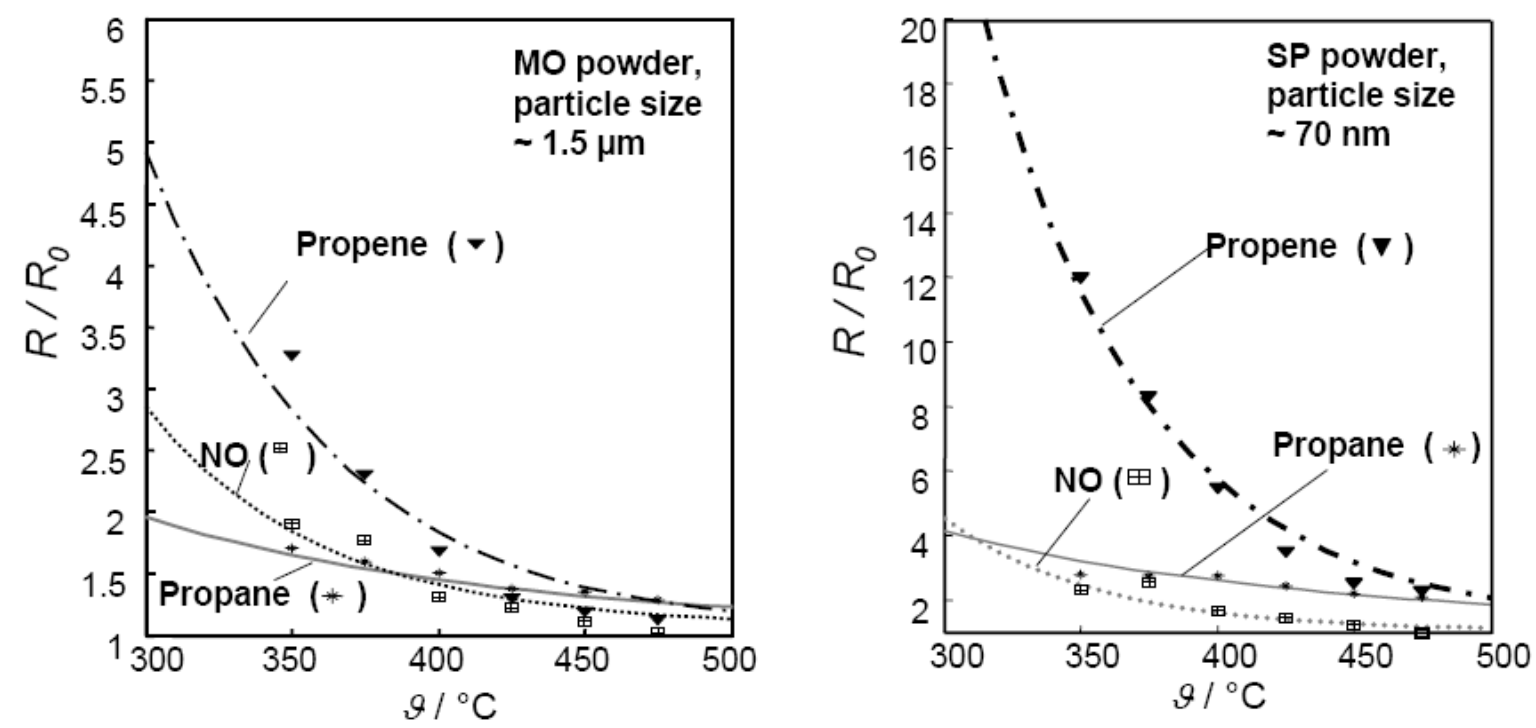


\subsection{Zeolites}

The versatile materials class of zeolites (Class of aluminosilicates with the general sum formula $\mathrm{Me}_{\mathrm{y} / \mathrm{m}}^{\mathrm{m}+}\left[\left(\mathrm{SiO}_{2}\right)_{\mathrm{x}} \cdot\left(\mathrm{AlO}_{2}^{-}\right)_{\mathrm{y}}\right] \cdot \mathrm{zH}_{2} \mathrm{O}$ [105]. The tetrahedral silica and alumina building blocks form a 3-dimensional framework, in which cations $\mathrm{Me}^{\mathrm{m}+}$ compensate the residual negative charge caused by the alumina atoms.) with a 3D-framework, ion-exchange capacity, and/or catalytic activity has received increasing attention in various applications. Due to their unique property spectrum, zeolites are of particular interest in the field of gas sensing [106-108]. In a large portion of the corresponding literature, these materials figure as a mere auxiliary phase. They are applied for example as a filter to prevent cross-interfering species from reaching the sensor surface or as an inert matrix to encapsulate the gas-sensitive agent e.g. [109-112]. However, research work in Germany has recently focused on devices where the zeolite itself acts as the sensitive element.

After studying the effect of water vapor and polar organic molecules on zeolite conductivity in the temperature range from $40{ }^{\circ} \mathrm{C}$ to $110{ }^{\circ} \mathrm{C}$, several German groups proposed (Guth et al., Fetting et al. and Plog et al.) coworkers were the first to propose a corresponding conductometric sensor concept for humidity and combustible gases [113-116]. Some years later, Simon and co-workers proposed an impedimetric zeolite-based sensor for humidity detection $\left(400{ }^{\circ} \mathrm{C} \leq T \leq 600^{\circ} \mathrm{C}\right)$ in harsh environments [117]. Here, the impedance of a Si-rich zeolite film was found to respond linearly and reversibly even to traces of humidity. Assuming an adsorption-desorption equilibrium of water molecules in the zeolite framework, the effect was attributed to a solvate supported proton transport.

Earlier results by the Simon group provided the basis for the development of a highly selective zeolitic ammonia sensor [118]. While studying the effect of ammonia on dehydrated zeolite BEA, they observed an increase in the protonic bulk conductivity of the material. These findings were attributed to the adsorption of $\mathrm{NH}_{3}$ molecules, which support the proton transport from one aluminum site within the zeolite framework to the next [119]. Since the effect depends essentially on the amount of adsorbed $\mathrm{NH}_{3}$, i.e., on the ammonia partial pressure $\mathrm{pNH}_{3}$, proton-conducting zeolites are promising candidates for conductometric or impedimetric ammonia sensors. The robust impedimetric zeolite sensor element discussed in [120] was intended for automotive exhaust gas applications and presented no significant cross-interference of hydrocarbons, $\mathrm{CO}_{2}, \mathrm{CO}$, and $\mathrm{O}_{2}$ when operated at $420{ }^{\circ} \mathrm{C}$.

In later work [121], Simon et al. discussed a similar sensor concept using proton-conducting zeolite MFI for conductometric amine detection. Also in this case, reversible and concentration dependent changes of conductivity with a fast response time were observed. However, a refined model of interaction of the amines with the mobile protons of the zeolite remained unsolved.

The Moos group reported a novel ammonia sensor using Fe-loaded zeolites of the framework type MFI [122]. This material is known as a highly active candidate for the selective catalytic reduction (SCR) of $\mathrm{NO}_{\mathrm{x}}$ with ammonia, a catalyst concept discussed for automotive exhaust gas aftertreatment [123]. The high-temperature stable zeolite was applied directly as the functional sensor film. By measuring its impedance at $500{ }^{\circ} \mathrm{C}$, selective ammonia sensor elements were obtained. At this temperature, only comparatively high concentrations of $\mathrm{NO}_{2}$ and propane caused a small crossinterference whereas the NO sensitivity was negligible. The same group also used the same zeolite without Fe-doping to prepare a mixed-potential ammonia sensor for automotive applications [6]. The 
system MFI,Au / YSZ / Au presented a high ammonia sensitivity with the additional advantage to optimize independently the electrode (Au) and the zeolite catalyst (MFI) layer.

In addition to bulk effects within the zeolite framework, interface effects between the zeolite and an adjacent material may cause a sensor response. Hagen et al. studied this effect by comparing Pt-loaded zeolite $\mathrm{MFI} / \mathrm{Cr}_{2} \mathrm{O}_{3} / \mathrm{Au}$ to Pt-loaded zeolite $\mathrm{MFI} / \mathrm{Au}$ [124] and by using four-probe impedance spectroscopy [125]. They showed that the sensor response to hydrocarbons, i.e., a pronounced increase of the low frequency impedance, only occurs in the presence of the metal oxide interfacial layer between the zeolite and the electrodes. If the zeolite $/ \mathrm{Cr}_{2} \mathrm{O}_{3}$ interface is missing, the sensor device looses functionality. This discovery led to the successful transfer of the sensor concept from thin film processing to more cost-effective film technology without using PVD or vacuum processes [126]. A very selective sensor element was prepared, which was almost insensitive toward $\mathrm{H}_{2}, \mathrm{CO}, \mathrm{NO}, \mathrm{CO}_{2}$ and $\mathrm{O}_{2}$ (if oxygen is available in excess). In recent work, Fischerauer et al. discussed a mechanistic model of the sensing mechanism [127] taking into account the ionic conductivity of the zeolite and the p-type semiconductor properties of $\mathrm{Cr}_{2} \mathrm{O}_{3}$. In addition, the blocking electrode characteristics of the zeolite $/ \mathrm{Cr}_{2} \mathrm{O}_{3}$ interface were included. By this model, the charge carrier density in the $\mathrm{Cr}_{2} \mathrm{O}_{3}$ film was identified as a crucial parameter influencing the sensor current. Since the ambient hydrocarbon concentration modulates this density due to conventional semiconductor-gas interactions (confer Section 3.1), the sensor current and hence the impedance spectra respond to concentration changes.

It should be noted here that gas sensor research is just at the outset of possibilities arising from utilizing framework structures materials. This topic is not restricted to inorganic materials with channels and pores but may be greatly enlarged to organic materials. One example shall complete this section. Very recently, metal-organic framework (MOF) materials were investigated as impedimetric gas sensor materials in the range $120{ }^{\circ} \mathrm{C}-240{ }^{\circ} \mathrm{C}$. They show very reproducible responses to water [128] without being affected by $\mathrm{O}_{2}, \mathrm{CO}_{2}, \mathrm{C}_{3} \mathrm{H}_{8}, \mathrm{NO}$, or $\mathrm{H}_{2}$.

\subsection{Further Approaches for Selectivity Enhancement}

A newly reported promising way for the improvement of the sensing capability of semiconducting metal oxides is to keep the base chemistry of the materials as it is and to work on "physical" methods to get to new sensitivities. Important improvements in this field came from Kohl et al. (University of Gießen). One relates to the notion that many oxides at elevated temperatures are mixed conductors. The usage of a polarizing electrical field during the measurement leads to a movement of bulk donors and results in changes of the surface charge. Instabilities as well as changes of sensitivity may occur due to that and are described in models. This leads to general considerations about improving the result by a careful selection of the dynamic measurement procedure [129]. The other approach imposes nanosized surface corrugations on materials with known chemistry. These mesoporous materials are created by structure replication e.g. hexagonal mesoporous silica variants. The sensitivity here obviously depends not only on the surface-to-volume ratio, but also on the nanoscopic structural properties of the base materials [130,131].

The University of Hamburg and Sony Research, Stuttgart (Vossmeyer) pursue a novel way of conductometric readout of non-oxidic materials that is targeted to a new generation of low-power / room temperature operated sensors [132]. They use nanoparticles from noble metals that are embedded 
in a cross-linked way in dendrimetric organic materials. This matrix stabilizes the nanoparticles. Readout can be done mass sensitive (quartz microbalances) as well as conductometric by the application of such a film on an interdigitated electrode structure. With conductometric readout the resistances changes to gas exposures are relatively small (below $1 \%$ relative change) but appear to be exploitable due to a low $\mathrm{S} / \mathrm{N}[133,134]$ The aim is to arrive at a selective adsorption of guest molecules from the gas phase

\subsection{Novel Deposition Techniques}

Driven by the growing need for high performance gas sensors, a large number of innovative deposition techniques have been introduced and investigated. Compared to standard thick and thin film processes, the novel methods either present with direct-write features or offer precise control of microand nano-structural features of the deposited materials [135].

Among the most cost-efficient novel techniques feature various types of suspension-free spray deposition. Since no solvent needs to evaporate, these techniques present a major advantage over the wet sol-gel based coating methods. Hence, the films are more homogeneous and less prone to cracking. At the University of Tübingen [76], flame spray pyrolysis was studied for gas sensor preparation (results see Section 3.1). This versatile and effective technique allows to produce metal oxide powders and to deposit thin films with the possibility to control film morphology and powder particle size in the nm range. After formation in the flame by nucleation, coagulation, and coalescence, nanoparticles undergo direct (in situ) deposition onto suitable sensor substrates. A very fast and clean single step process for sensor preparation is thereby obtained. The resulting thick films are highly porous and present a large accessible surface, which makes flame spray pyrolysis a promising candidate for rapid and low cost sensor production. Quality and properties of the films and powders depend on the process parameters. In [136], highly porous pure or Pt-doped $\mathrm{SnO}_{2}$ powders were prepared by direct flame spray synthesis. The synthesized powders were screen-printed and annealed at temperatures up to $500{ }^{\circ} \mathrm{C}$. With these devices, $\mathrm{CO}$ concentrations well below $10 \mathrm{ppm}$ were detected. Functional nanoparticles were directly deposited from the aerosol phase onto standard sensor substrates forming highly porous films [137]. By repeating layer deposition, multilayer structures were prepared consisting of doped and undoped gas sensitive $\mathrm{SnO}_{2}$ and $\mathrm{Al}_{2} \mathrm{O}_{3}$ as a filter layer.

As another spray method, the aerosol deposition technique has recently been investigated for gas sensor preparation at University of Bayreuth [138]. This low-temperature technique was first proposed in 1999 as a simple method for the preparation of dense piezoelectric films at room temperature [139]. In a continuously shaken aerosol generator, the precursor powder is fluidized. Using a vacuum pump, the carrier gas stream loaded with powder particles is then accelerated towards the substrate. If the various process parameters, e.g. powder particle size, flow rate, or vacuum conditions, are carefully adjusted, the impact energy is sufficient to prepare a dense layer on the substrate without the need for a sintering step at high temperatures. For some materials, this low-temperature deposition process might simplify the sensor preparation to a large extent. One example is the $\mathrm{SrTi}_{1-\mathrm{x}} \mathrm{Fe}_{\mathrm{x}} \mathrm{O}_{3-\delta}$ perovskite system with its promising temperature-independent oxygen sensor characteristics (cf. Section 3.2 for details). When prepared by the conventional screen-printing technique, $\mathrm{SrTi}_{1-\mathrm{x}} \mathrm{Fe}_{\mathrm{x}} \mathrm{O}_{3-\delta}$ films present a stability problem during sintering at $1,200{ }^{\circ} \mathrm{C}$ when in direct contact with alumina. In an initial feasibility 
study, $\mathrm{SrTi}_{0.7} \mathrm{Fe}_{0.3} \mathrm{O}_{3-\delta}$ sensor films were prepared at room-temperature by low-temperature aerosol deposition. The spray-deposited films presented a dense and homogenous microstructure (confer Figure 11b) with an excellent adhesion to the substrate. The oxygen sensing behavior of the films was assessed and found to be in perfect agreement with earlier literature data on this material [49].

Figure 11. One sensing material, different microstructures: (a) Porous $\mathrm{SrTi}_{1-\mathrm{x}} \mathrm{Fe}_{\mathrm{x}} \mathrm{O}_{3-\delta}$ film prepared by conventional screen-printing. (b) Aerosol-deposited compact layer. (c) $\mathrm{SrTi}_{1-\mathrm{x}} \mathrm{Fe}_{\mathrm{x}} \mathrm{O}_{3-\delta}$ fiber structures obtained by electrospinning.

(a)

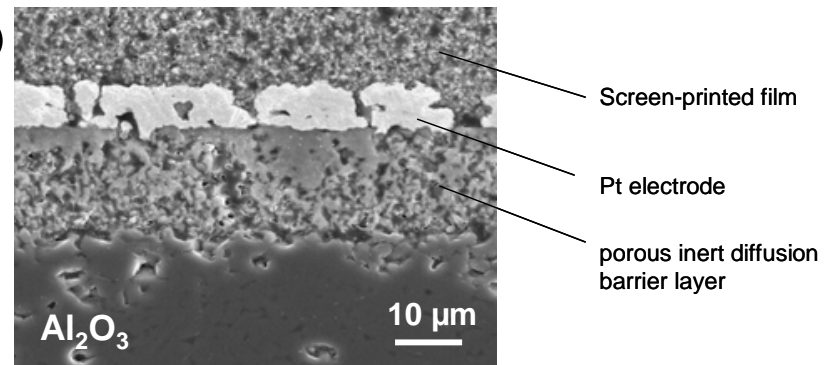

(b)

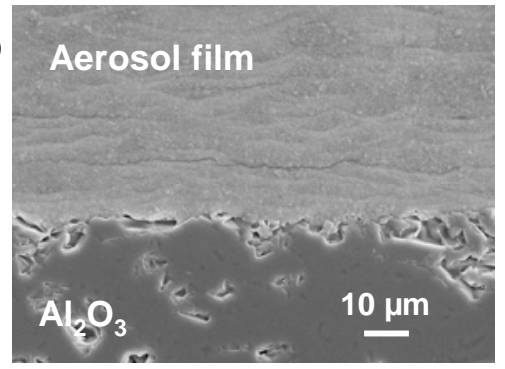

(c)

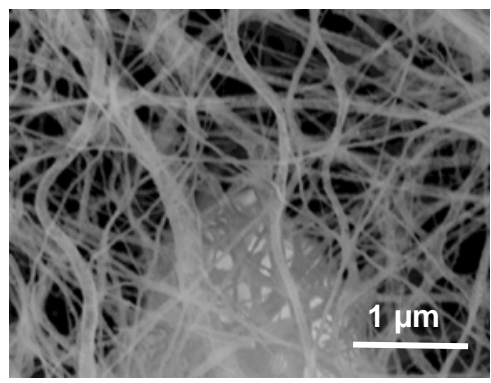

Due to the high surface-to-volume ratios achieved by electrospinning, this novel deposition method is a very promising tool for the preparation of conductometric sensor elements. Its operational principle relies on electric forces used during deposition. A high voltage, in the $\mathrm{kV}$ range, is applied between a substrate and the needle of a syringe, which contains the precursor solution and is operated by a programmable syringe pump to achieve a constant delivery rate. The precursor solution is prepared by adding an appropriate polymer solution to the unreacted solvated components of the sensor material. An important feature is the choice of an effective, highly volatile solvent, which evaporates in-situ. Appropriate systems are polyvinylpyrollidone (PVP) in ethanol or cellulose acetate (CA) in acetone. Under the action of the electric field, a fine polymer fiber network forms, which encapsulates the metal oxide precursor. During a subsequent thermal treatment, the polymer matrix is removed, and ceramic nano-wires remain on the substrate. In a collaborative study, researchers at University of Bayreuth investigated this technique for the preparation of fiber networks of ternary $\mathrm{SrTi}_{1-\mathrm{x}} \mathrm{Fe}_{\mathrm{x}} \mathrm{O}_{3-\delta}$ perovskites as shown in Figure 11c. The hydrocarbon sensor characteristics of the electrospun fibers were superior to those observed with conventional devices prepared by screenprinting of microscaled powders [102].

In addition, the Simon group at RWTH Aachen and the Maier group at University of the Saarland directed considerable research effort to high-throughput methods for screening gas sensor materials. These methods, originally developed for pharmaceutical purposes, allow investigation of a multiplicity of materials prepared in the form of "libraries". Compared to the conventional 'one at a time' strategy, 
this accelerates material synthesis and characterization. In [140], $\mathrm{ZnO}$ and $\operatorname{In}_{2} \mathrm{O}_{3}$ nanoparticle films were prepared on multi-electrode substrates using a laboratory roboting unit and functionalized with various noble metals by surface doping. High throughput impedance spectroscopy was used to identify the most suitable candidates for NO sensing. A similar technique was used in [141,142] to screen the gas sensing properties of a large variety of semiconducting metal oxide materials. An overview of the modus operandi is given in [143]. Besides the rapid identification of suitable gas sensor materials, the groups aim at the understanding of composition-to-property relations in semiconducting metal oxide nanoparticles.

\section{Field Effect Sensors}

Another very promising technique for low cost/low power gas sensors is the work function readout via field effect devices, which was first introduced with the $\mathrm{H}_{2}$-sensitive field effect transistors with heated Pd-gate [144]. In this case, $\mathrm{H}_{2}$ diffusing through the Pd-gate applied directly on the channel isolation of a FET-structure produces a potential at the $\mathrm{Pd} /$ channel insulation interface that modulates the drain-source current. Also called "Lundström-FET", this approach is somewhat limited in terms of detectable gases. However, it triggered research on a multitude of sensor variants. They directly use an electrical potential arising due to gas adsorption at the sensitive material. This gas adsorption at the surface leads to what physicists call a change in the work function and chemists a change in the electro-chemical potential. Obviously it is quite easy to control since it directly relates to surface properties and is not affected by the multitude of effects of electrical currents crossing a solid state sensor device.

\subsection{Device Technology}

The size of these surface potential changes is in the order of $100 \mathrm{mV}$ at suited sensitive materials and thus it can be used to drive a FET device. A sketch of the setup is shown in Figure 12. The insulation of the transistor channel has to be made of a chemically inert material to avoid additional gas reactions at this surface; otherwise an additional potential change occurs there. The usage of LPCVD deposited $\mathrm{Si}_{3} \mathrm{~N}_{4}$ has shown to be a good choice for that.

Figure 12. Scheme of a suspended gate GasFET. The gate electrode is suspended and covered with a gas sensitive layer. The electrical potential generated by gas adsorption acts as an additional gate voltage and changes the source-drain current. Reprinted from [150] with permission from Elsevier.

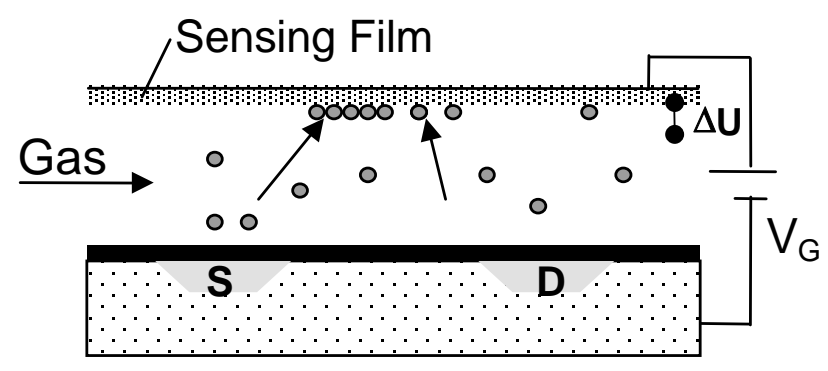


Besides Janata [145], the pioneers in the construction of such type of set-up were Eisele and Doll $[146,147]$, who used a hybrid approach with one part being a gateless FET done with conventional Sitechnology and the other a substrate equipped with a sensing film, both brought together to form a gas sensor. The weakness of such a device is that due to the small capacity of the air gap, only a small portion of the generated potential is actually driving the FET. Following work from Gergintschew [148], several options have been introduced to make more efficient use of the generated voltage. One significant improvement consists of the formation of a larger area capacitor build from the suspended gate and a floating gate. The floating gate then transmits the potential coming from the gas sensitive layer to a small FET-device with a short channel [149]. This basically minimizes the loss of sensing signal due to weak coupling via the air gap (Figure 13).

Figure 13. Schematic cross section of a floating gate (FGFET) type transducer that improves the coupling of the work function voltage to the FET. The capacitance well electrode can be additionally used to set the optimal working point in the transistor characteristics.

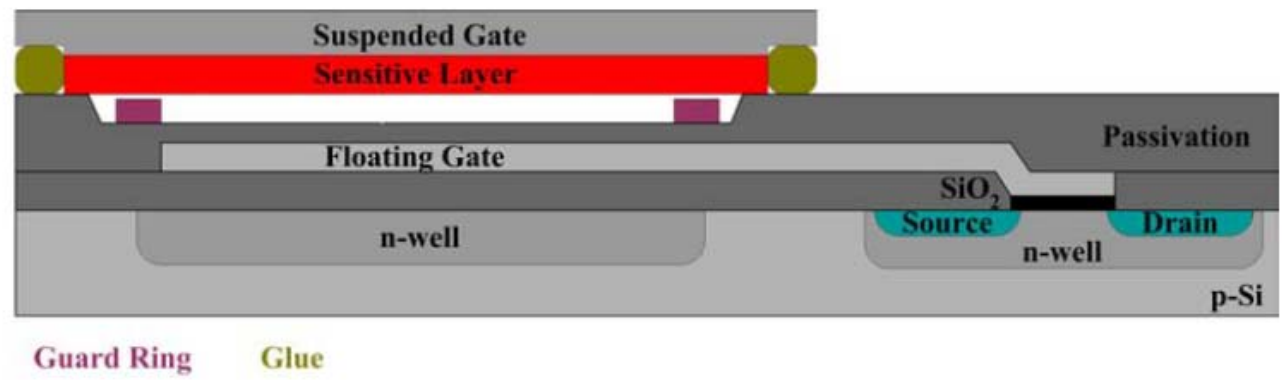

For industrialization, a flip-chip variant of this device was designed, allowing easy mounting, a precise definition of the air gap, and low-processing temperatures [150]. The base idea for the formation of the air gap here is to have a channel in the Si and to mount the gate chip with a large flat surface area of the sensing layer in direct contact with the chip surface. The current state of this sensing technology is depicted in Figure 14:

o An appropriate sensing material is deposited on a flat carrier substrate forming what eventually becomes the gate-electrode. The preparation conditions are not limited by any Sielectronics related constraints.

o The Si FET-chip is separately prepared in standard CMOS. Electronics for driving the sensor may be integrated in the Si-Chip

o Finally both parts are bonded together so that a defined air gap is formed.

Using an open gate FET in a setup like in Figure 14, the change in work function can be directly measured with a small device. When four FET-devices are included in the Si-Chip, they can be combined with four different sensing materials. Hence, a very compact sensor array can be constructed [151]. Alternatively, FET channels can be used to compensate for the influence of varying ambient temperature on the FET itself, or special temperature independent operation conditions of single transistors ("isothermal point" of the transistor characteristics) are chosen. 
Figure 14. Actual state of the art of a GasFET: the gate part carrying the sensitive layers is glued to the silicon chip (below). The white ceramic part is a carrier that might be used to host the small chip. Attaching the sensitive layer to this ceramic constitutes an alternative construction of the device.

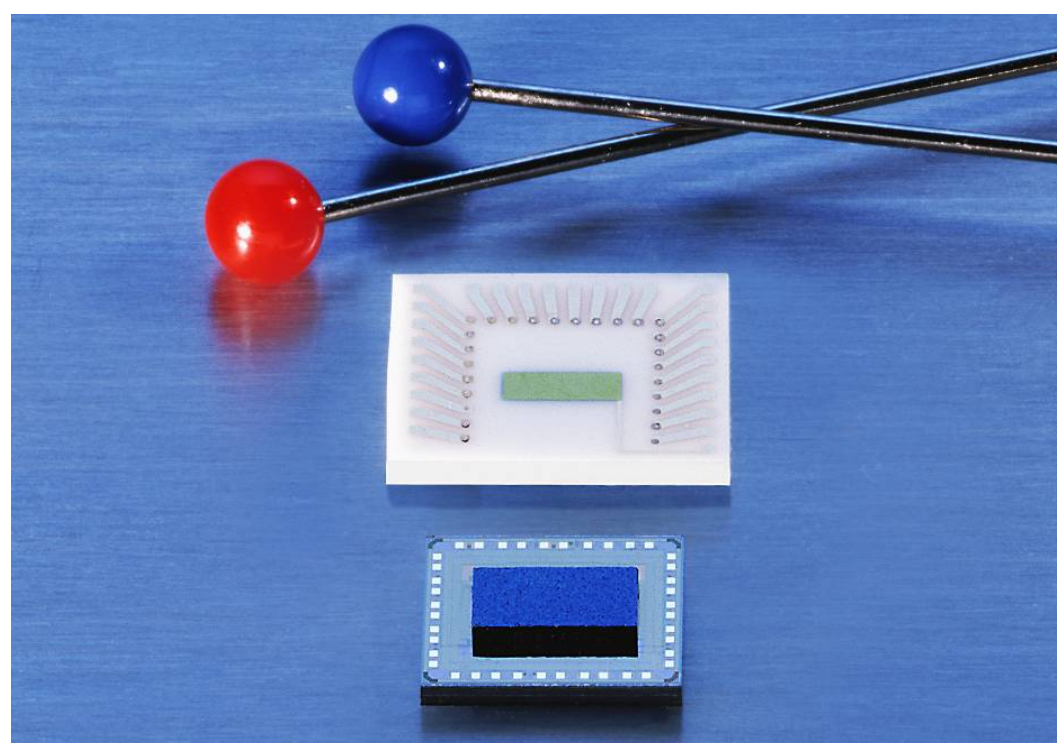

These sensors are characterized by an unprecedented freedom in the choice of sensing materials. The gas receptor does not need to be an oxide. Organic molecules, polymers, metals, or salts may be used in the sensing platform. Since the sensors can be operated at room temperature, heating is not required. Multiple readout channels allowing for tiny sensing arrays can be realized on one single chip.

The base potential of this sensing technology arises from the fact that the measurand comes from the direct measurement of surface effects. One consequence is that sensing materials in these devices do not need to be a semiconductor: metallic conductors or insulating materials can be used as well.

\subsection{Gas Sensing Materials for Suspended Gate FETS}

Similar to direct thermoelectric gas sensors (cf. Section 1.4), in contrast to classical semiconducting metal oxide gas sensors, the gas sensing properties do not depend on the morphology of the sensing materials. An example demonstrating this has been found during the investigation of gas-induced work function changes of TiN. TiN is quite inert in view of its chemical properties, but has been found to react mainly with $\mathrm{NH}_{3}$ and thus can be used as a selective material for $\mathrm{NH}_{3}$ detection in environmental air. The preparation of TiN as a sputter-deposited compact thin film and as screen printed porous thick film resulted in the same gas sensing properties due to the fact that mainly the TiN surface determines the gas sensing characteristics [152,153], see Figure 15. Since the device is working at room temperature, no heating power is required. The TiN-based sensor serves also as a nice example for a sensing material with metallic conductivity. 
Figure 15. Work function change of two different preparations of $\mathrm{TiN}$ at room temperature in response to $\mathrm{NH}_{3}$ exposure in wet synthetic air measured with the Kelvin method. Reprinted from [152] with permission from Elsevier.

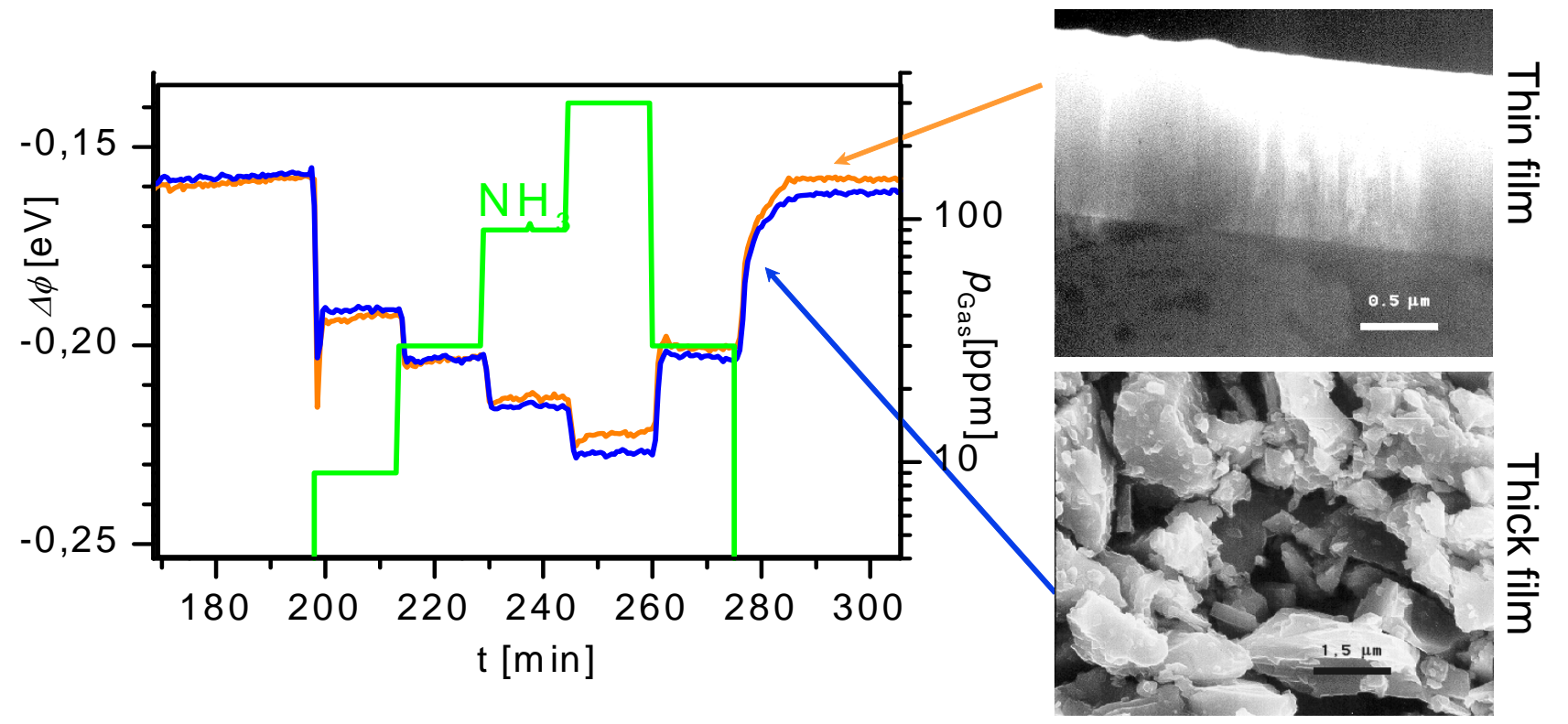

Several noble metals showing a stable surface configuration are applied detection layers. They comprise noble metals like Pt [154] or Pd [155] for $\mathrm{H}_{2}$ detection. Especially with the adsorption of $\mathrm{H}_{2}$ on Pt, amazingly high surface potential changes of $500 \mathrm{mV}$ and more are observed. The reason for this can be seen in the high reactivity of $\mathrm{Pt}$ to $\mathrm{H}_{2}$ even at room temperatures. The problem with high sensitivities is that the strong reaction with $\mathrm{H}_{2}$ implies a strong influence on the "natural" adsorbates on these sensing layers. In this case, it is a removal of the adsorbed oxygen on the Pt surface, which is reconstituted only after long periods, thus causing some hysteresis effects after repeated strong $\mathrm{H}_{2}$ expositions. This leads to a new operation strategy for the reactive $\mathrm{Pt}$, which is further coated with a gas diffusion filter [156]. Now, the differences in the diffusion of $\mathrm{O}_{2}$ and $\mathrm{H}_{2}$ cause the major sensing effect, significantly improving the reproducibility of the sensor readings for $\mathrm{H}_{2}$.

$\mathrm{Au}$ is another example for a stable metallic sensor materials, which is suitable for the detection of strongly oxidizing gases like $\mathrm{NO}_{2}$ or $\mathrm{O}_{3}$ [157]. Semi noble metals like Ag are reported to be sensitive to $\mathrm{H}_{2} \mathrm{~S}$ and $\mathrm{Cl}_{2}$ [158].

This leads to the metal oxides that form a large group of sensing layers suited for GasFETs. In contrast to the heated semiconducting metal oxides, which are a broad band sensor for reducing or oxidizing gases, metal oxides at room temperature do not show a significant reaction to the reducing capability of gases. This is demonstrated by an absence of a sensor effect to small reactive hydrocarbons using polycrystalline layers of porous $\mathrm{Ga}_{2} \mathrm{O}_{3}$ and work function readout. Such a layer, however, is reactive to solvents that couple to the metal oxide through their functional groups [159]. 
Figure 16. Reaction of a porous $\mathrm{Ga}_{2} \mathrm{O}_{3}$ thick film at room temperature in wet synthetic air to ethanol. No signal to reactive small hydrocarbons (ethane, ethene, ethine, propane mixture) in the range of $1,000 \mathrm{ppm}$ is observed.

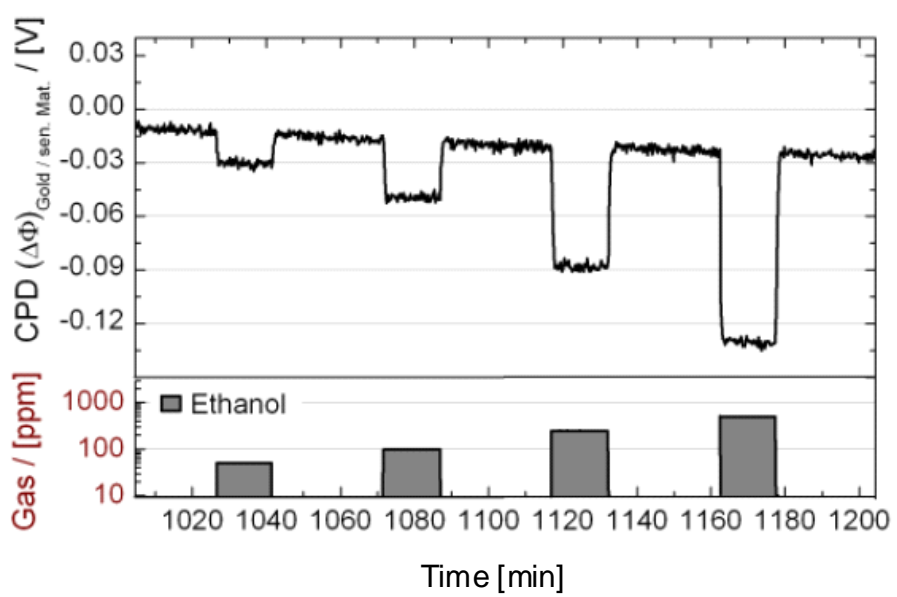

Figure 17. Work function change of the $\mathrm{Ga}_{2} \mathrm{O}_{3} / \mathrm{Pt}$ system to a reducing gas (CO) and ethanol at room temperature in wet synthetic air: (a) Immediately after preparation (last thermal budget $700{ }^{\circ} \mathrm{C}$ for $2 \mathrm{~h}$ to form nano-dispersed Pt. (b) After $800 \mathrm{~h}$ storage at room temperature. (c) After storage and thermal activation at $175^{\circ} \mathrm{C}$ for 5 mins. The thermal activation worked repeatedly during all experiments.
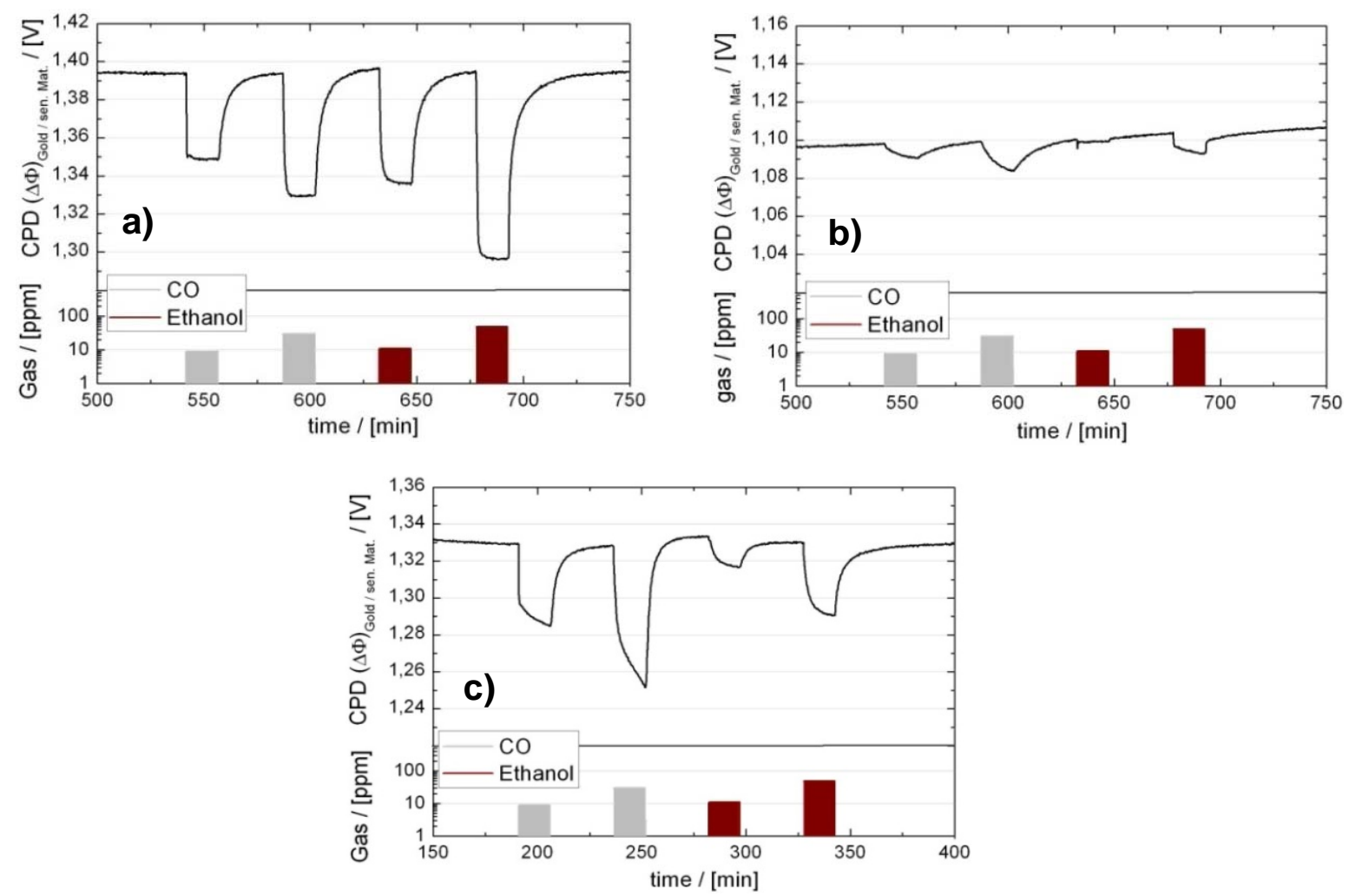

Using films of metal oxides that carry a catalyst dispersion, a reactivity to the reducing character of gases can be obtained even at room temperature, when a thermal activation was done. Figure 17 illustrates this for a nanosized catalyst dispersion supported on a polycrystalline $\mathrm{Ga}_{2} \mathrm{O}_{3}$ sensing layer. 
This layer is developed to create a room temperatures-operated TVOC (total volatile organic compounds) sensor. Without activation, the sensitivity is almost completely lost. Using an intermittent thermal activation at moderate temperatures $\left(<200{ }^{\circ} \mathrm{C}\right.$ in wet room air that might be done one time daily for a few minutes), a sensitivity for all tested reducing gases can be maintained, even when the sensing material is operated at room temperature. Obviously some reactive oxygen species are formed during the thermal activation. They are the stored in the sensing material [160]. The oxide enhances the lifetime of the activated species. Using only Pt as sensing layer, the gas sensitivity declines after a few hours after thermal activation. Using the $\mathrm{Pt} / \mathrm{Ga}_{2} \mathrm{O}_{3}$ systems, the gas sensitivity is preserved at least one order of magnitude longer. Sensitivity to all gas groups relevant for indoor air smell monitoring can be achieved with a proper combination of finely dispersed Pt and thermal activation [160].

Also the classical $\mathrm{SnO}_{2} / \mathrm{Pd}$ system can be used to detect $\mathrm{CO}$ (Figure 18). According to the model with the formation of some reactive oxygen species at the surface, it needs some intermittent thermal activation. Then, $\mathrm{CO}$ can be detected even at room temperature with the $\mathrm{SnO}_{2} / \mathrm{Pd}$ system $[161,162]$. Selectivity to interfering gases is roughly comparable to the classical heated conductometric semiconducting $\mathrm{SnO}_{2} / \mathrm{Pd}$ sensors.

Figure 18. Sensing characteristics towards $\mathrm{CO}$ in ambient air of a GasFET equipped with a polycrystalline sensing layer of Pd-doped $\mathrm{SnO}_{2}$. In the inset, the size of $\mathrm{SnO}_{2}$ crystallites with the impregnated Pd clusters are shown. Measurements were conducted at room temperature after a preceding thermal activation. Reprinted from [162] with permission from Elsevier.

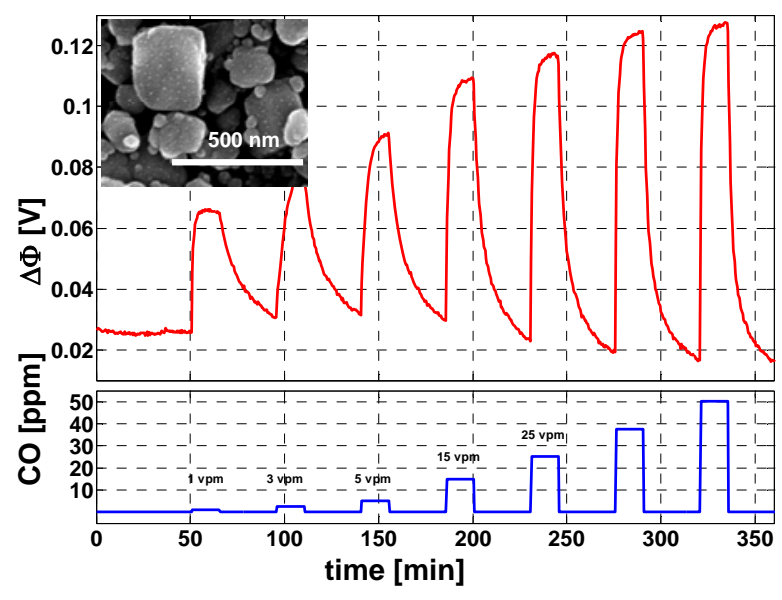

Even sensors for gases that are hard to detect with semiconducting metal oxide gas sensors could have been implemented due to the versatility in the chemical structure of the sensitive layer. In one example, the base idea was to work with carbonate-based sensing layers, since they show some chemical similarity to $\mathrm{CO}_{2}$. The best material found in this system was $\mathrm{BaCO}_{3}$. It appeared to be a reversible sensing material for $\mathrm{CO}_{2}$ even at ambient temperature [163]. Again, the sensitivity is independent on the morphology (Figure 19a). Thin films prepared by a colloidal suspension showed the same $\mathrm{CO}_{2}$ sensing characteristics like large-grained thick films. The slope of the sensor characteristics temperature independent within a certain range and obeys a logarithmic behavior 
(Figure 19b), which emerged to be typical for most work function based sensing materials over a wide concentration range.

Figure 19. Detection of $\mathrm{CO}_{2}$ with the $\mathrm{BaCO}_{3}$ system: (a) Work function change of two different preparations of $\mathrm{BaCO}_{3}$ at room temperature in response to $\mathrm{CO}_{2}$. (b) Sensor characteristics for $\mathrm{CO}_{2}$ detection in wet synthetic air. Reprinted from [163] with permission from Elsevier.
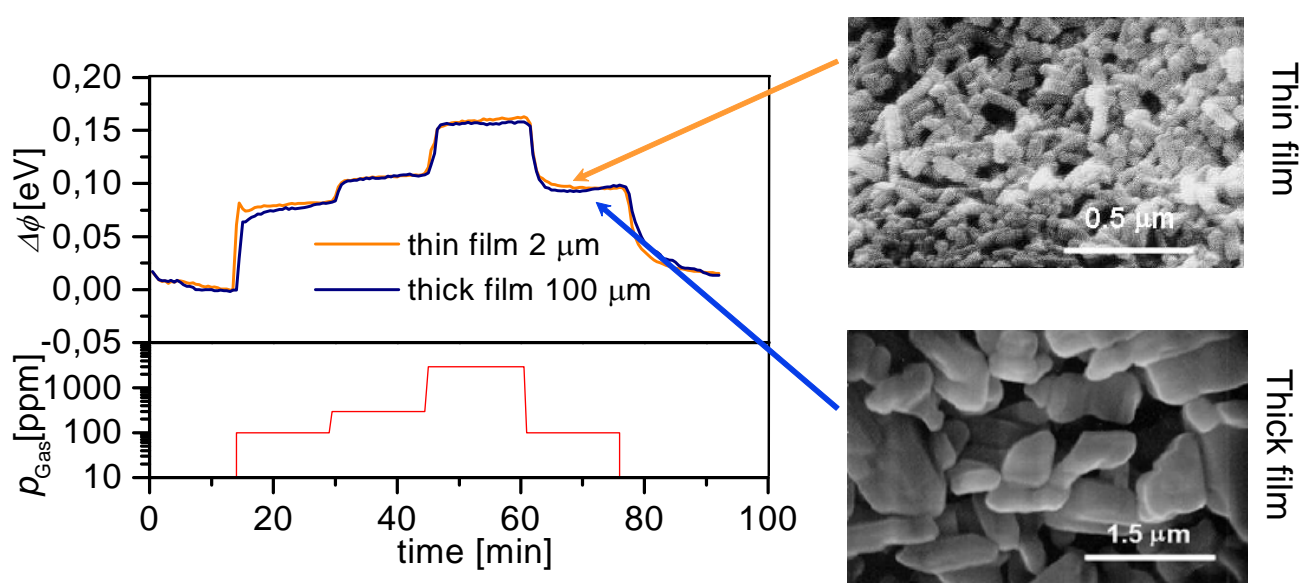

a)

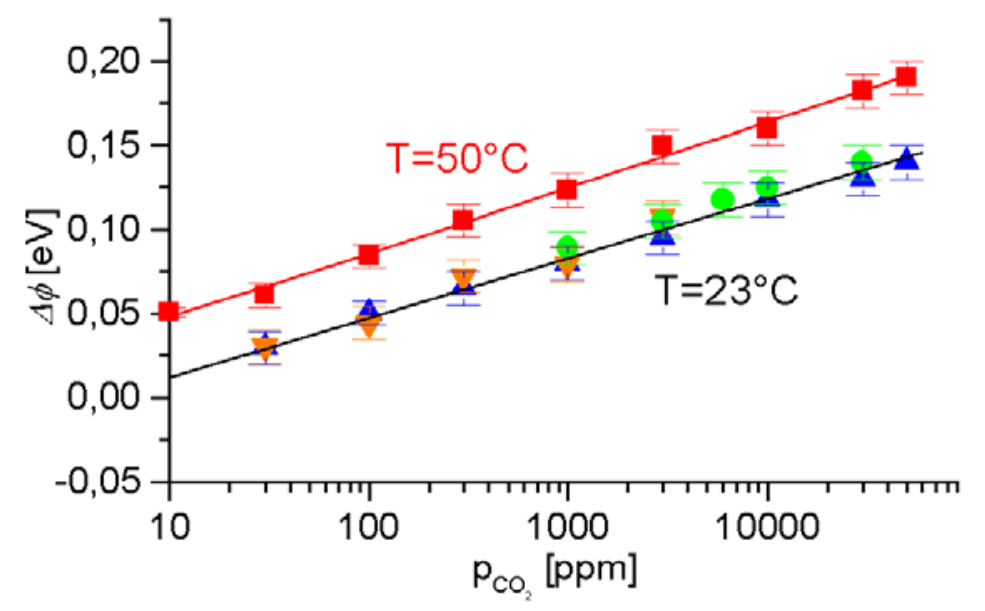

One obvious question with the gas detection by surface reaction at ambient temperature is the role of water in the detection process. In atmospheres with humidity, always several monolayers of water exist on the surface. They might hinder the gas sensing process. Results by Kelvin probe investigations demonstrated that the presence of humidity is necessary. The discussed $\mathrm{BaCO}_{3}$ films completely lose their $\mathrm{CO}_{2}$ sensitivity in absolutely dry atmospheres. IR spectroscopic investigations have shown that the $\mathrm{CO}_{2}$ detection process is a reversible formation of dimeric $\mathrm{HCO}_{3}{ }^{-}$in the water film on the surface [164]. These films are open porous, allowing gases to diffuse through the whole film and to reach the bottom electrode. Therefore, the electrode material has a significantly affects the cross sensitivity of the sensors [165].

Mixed oxide systems on the basis of $\mathrm{BaTiO}_{3} / \mathrm{CuO}$ [166] are also suitable for room temperature detection of $\mathrm{CO}_{2}$. The sensitivity is perhaps correlated with the formation of a surface phase of $\mathrm{BaCO}_{3}$. Following the approach of the acid-base reaction mechanism for the detection of $\mathrm{CO}_{2}$, even better results have been obtained with polymers that contain basic-type groups [167]. 
The class of polymeric materials turned out to be extremely powerful for this type of sensors. Besides materials like polysilsesquioxane that appeared to be selective sensors for solvents, the classical humidity sensing polymers can be incorporated into the FET sensing platform. Figure 20 shows two examples of such materials for humidity sensing [168]. The usage of these materials in the GasFET sensing platform is twofold. One is the direct readout of surface potentials. On the other hand, an active readout strategy can be pursued. Then, a voltage pulse is applied to the gate electrode and the following transient reaction of the source-drain current is evaluated. This mimics the capacitive readout of the polymers in the classical humidity sensors.

Figure 20. Polymers for humidity detection employed in the GasFET platform. Left: polyvinylpyrrolidone with classical work function readout. Right: polyamide readout by the gate pulse method. Both signals are compared to a standard capacitive humidity sensor.
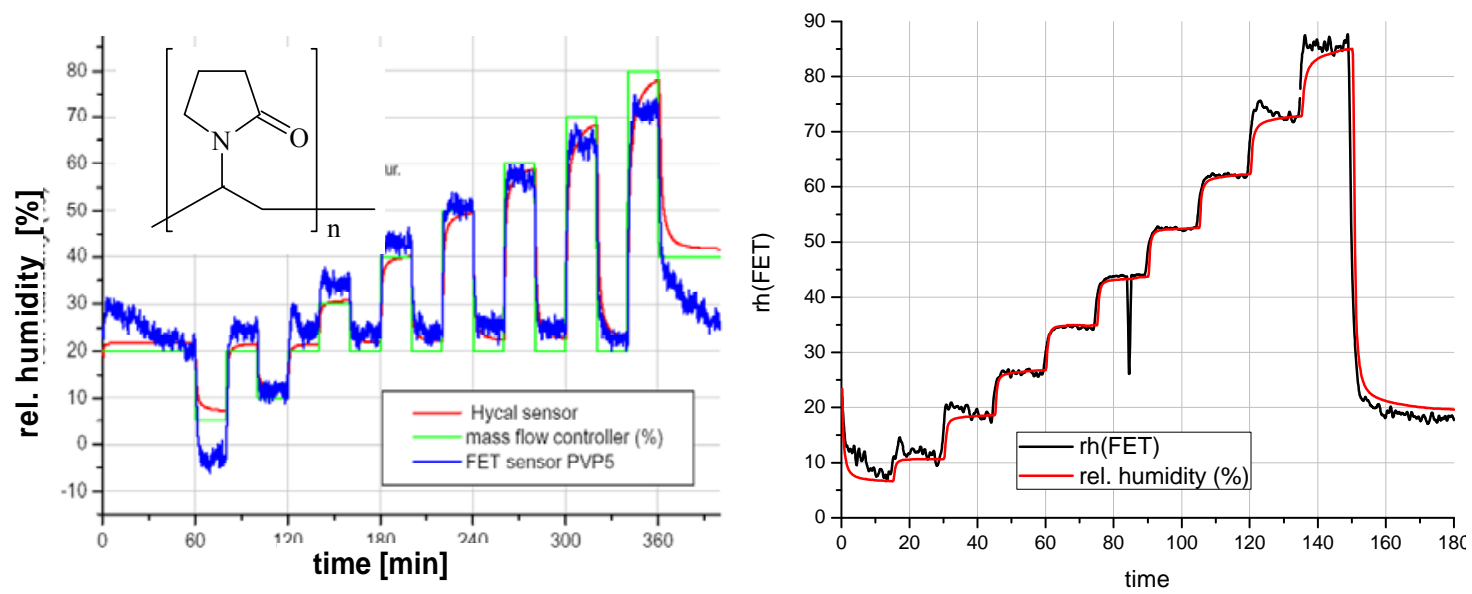

\subsection{Applications of GasFETs}

One promising field for applications of such sensors is air monitoring in buildings. Due to their small dimensions and moderate costs, they can be used for distributed sensing networks allowing local sensing of air properties. Due to their low power consumption at ambient temperature operation, battery-operated sensing nodes that communicate wireless can be established. Since there are no high labor costs for wiring, an additional and decisive cost advantage for the sensor user occurs.

An important application of such distributed sensors will be the control of the of indoor air quality to allow for an on demand ventilation of different locations in a building. Good examples are meeting rooms. Usually, when the room is unused the ventilation is too high, and is much too low, when a meeting takes place. Similar situations occur at work places due to the changing occupancy and due to the varying loading of the air with contaminants. The real air quality will be determined by measuring

o Temperature and humidity. The relative humidity (r.h.) has to be kept optimally at a level between $40-60 \%$ which is best for comfort as well as for the performance of people.

o The $\mathrm{CO}_{2}$-content: human breath enriches the air with $\mathrm{CO}_{2}$. At a level of $1,000 \mathrm{ppm}$, the first physiological reactions occur. Above 2,000 ppm people tend to become tired. 
o The overall smell level. Smell arising from human sources as well as from building components has a distracting effect, lowering the comfort level as well as the effectiveness of people. Some components have direct unhealthy effects.

The detection of all these quantities is required to come to a proper view on how inhabitants will perceive the environment. Due to the array capability and the versatility of the GasFETs, it will be the first time that a moderate cost solid state gas sensor detects all influential factors in various places in a building. The local sensing of the air quality will then allow for a local adjustment of the ventilation. The benefit of such improved air conditioning systems will not only be significant energy savings but also an increase in comfort. Extending the capabilities of the sensor array by developing and adding additional layers will allow detecting a wide range of possibly hazardous situations as well.

Figure 21. Detection of the lead gases for "smell" with a $\mathrm{Ga}_{2} \mathrm{O}_{3} / \mathrm{Pt}$ sensing layer with a room temperature-operated GasFET. To keep the sensitivity to the full gas spectrum, an intermittent thermal reactivation (e.g. once in the night for a few min) is necessary.
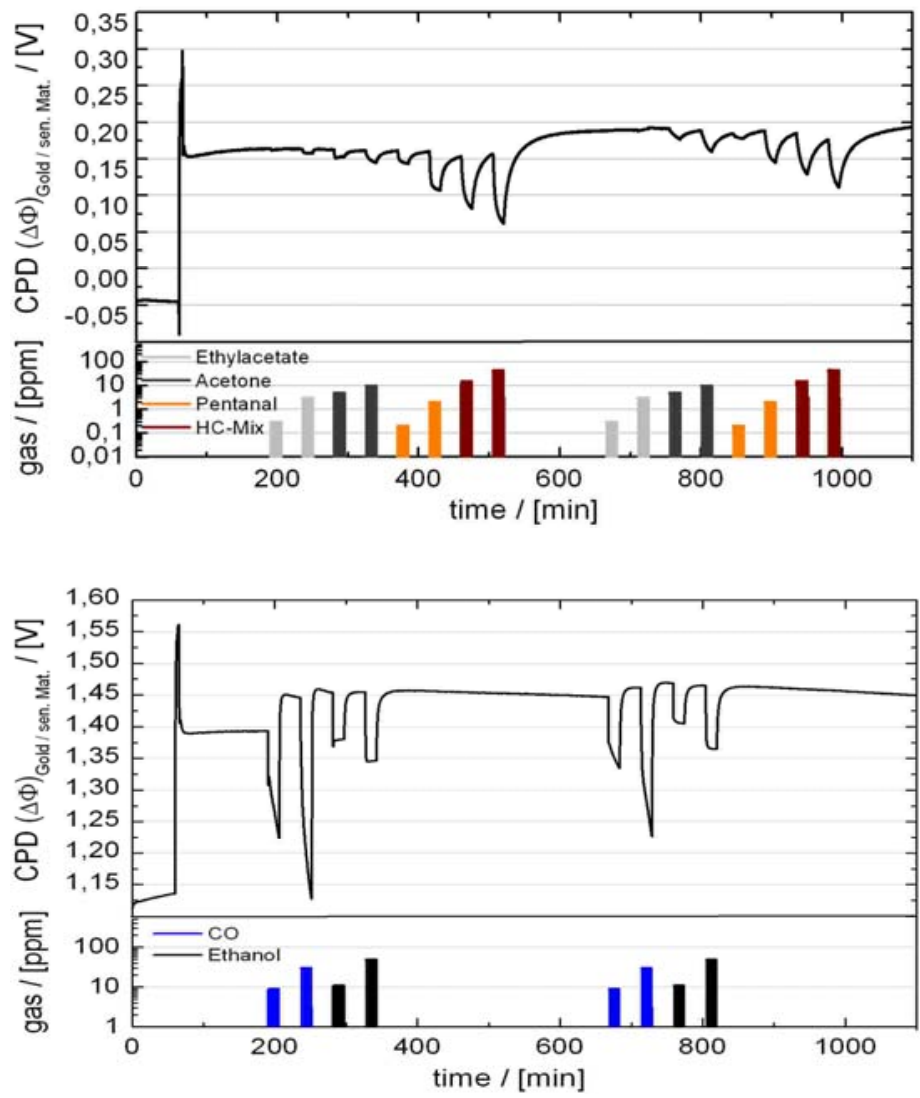

More complex than determining r.h. and $\mathrm{CO}_{2}$ is smell detection. An analysis of the indoor air with classical chemical analytical equipment like GC reveal the presence of hundreds of volatile organic compounds in indoor air with concentrations ranging from the sub-ppb to the ppm range. The development of receptor layers is not able to take this full range into account. The solution here is to group the gases into classes with similar chemical structure and reactivity to select a "lead-component" for the groups and to define a trigger level that is either adapted to the level of human smelling perception or to the maximum allowed exposure level. Typical classes are, e.g., aldehydes, alcohols, 
ketones, or unsaturated aliphatic hydrocarbons. All lead-components of these classes can be detected with a polycrystalline $\mathrm{Ga}_{2} \mathrm{O}_{3}$ sensing layer and a nano-dispersed Pt catalyst [160], see Figure 21 .

Besides the classical use of gas sensors, an upcoming application field for gas sensors are medical applications. This relates to the analysis of human breath with the goal to detect marker gases that are characteristic for metabolic malfunctions or diseases. In classical Chinese medicine, physicians smell the odor of their patient's breath to obtain an indication for their health state. The analysis of exhaled breath by gas sensors offers the potential for minimal disruptive measurements for diagnosis or therapy control. Since the marker gas concentrations are usually very low and since they need to be selectively detected, only advanced and versatile gas sensors can be used for these purposes.

A valid medical example for this is bronchial asthma, where the biomarker NO is already well established [169]. An increase of the regular value of 10-30 ppb of NO in the human breath to a threshold of $100 \mathrm{ppm}$ indicates pulmonary inflammation processes. For asthmatics, elevated NO has been validated as a reliable marker for the onset of an asthmatic crisis.

With the GasFET technology it seems possible to develop sensing systems being sufficiently selective, sensitive, and stable. No proper sensing layer for NO has been realized up to now, however, sensing layers based on $\mathrm{Cu}$-Phthalocyanine have shown the ability to selectively detect $\mathrm{NO}_{2}$ down to the ppb range [170]. An efficient $\mathrm{NO}$ to $\mathrm{NO}_{2}$ converter for human breath has been developed [171]. The base idea is to let pass the exhaled air through a two stage filter. The first stage consists of pure silica gel and removes excessive humidity from the breath. Silica gel which is impregnated with a strong oxidizing agent $\left(\mathrm{KMnO}_{4}\right)$ to oxidize $\mathrm{NO}$ to $\mathrm{NO}_{2}$ is the second stage (Figure 22). Results obtained at a gas flow $2.5 \mathrm{l} / \mathrm{min}$ showed an $\mathrm{NO}$ to $\mathrm{NO}_{2}$ conversion rate of $95 \%$ after the filter. Some loss of nitrous oxides due to adsorption on the filter has to be considered, but the actually obtained recovery of $\mathrm{NO}_{2}$ amounts to approx $90 \%$ and is therefore sufficient for this application.

Figure 22. Schematics of the $\mathrm{NO}$ to $\mathrm{NO}_{2}$ converter for human breath analysis. The gas passes through a two stage filter that dehumidifies and performs the oxidative conversion.

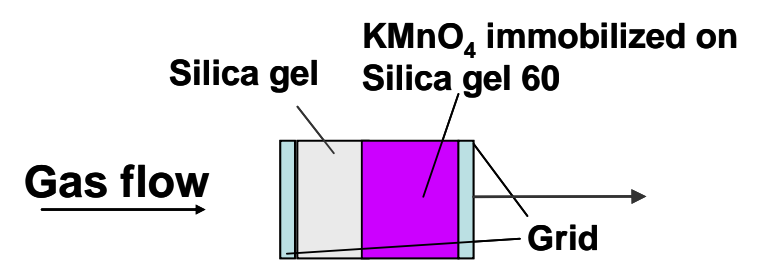

Sensors for selective detection of those low levels of $\mathrm{NO}_{2}$ are possible using the GasFET technology (Figure 23). They need to be heated to avoid possible condensation effects of water and sticking of $\mathrm{NO}_{2}$ on the walls and to respond sufficiently fast [172]. The results shown in Figure 24 demonstrate the ability of such systems to detect the increase of the NO concentration in human breath to the threshold of $100 \mathrm{ppb}$ which needs to be detected. Since these sensing systems are moderate in costs, they have the potential to provide an in-home warning and therapy control device for asthmatics, a group of persons which is a significant part of the population in industrialized countries - with rising tendency. 
Figure 23. $\mathrm{NO}_{2}$-Sensing behavior of GasFETs with $\mathrm{Cu}$-Phtalocyanine thin films: (a) Transient response of the work-function. (b) Sensing characteristics.

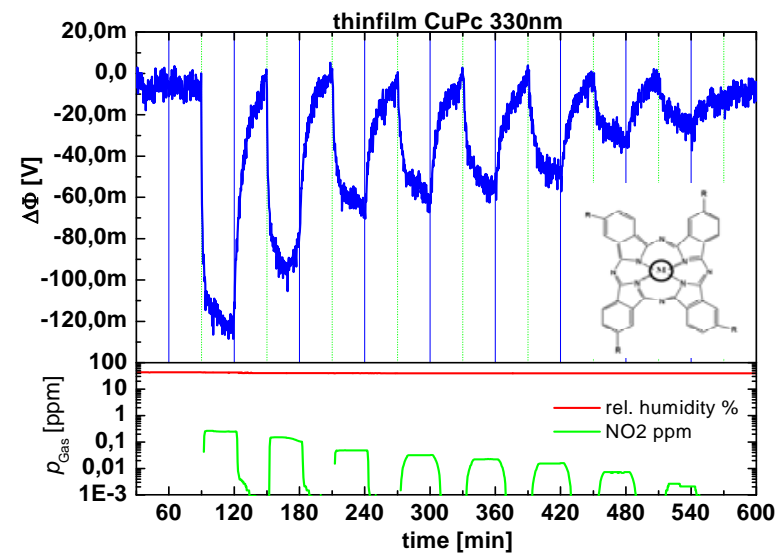

Figure 24. Results for the $\mathrm{NO}_{2}$ detection in simulated human breath using the $\mathrm{NO}$ to $\mathrm{NO}_{2}$ converter and a GasFET equipped with a $\mathrm{Cu}$-Phthalocyanine sensing layer. The rise of the NO content from the normal value of up to $30 \mathrm{ppm}$ to the threshold of $100 \mathrm{ppm}$ can be clearly separated.

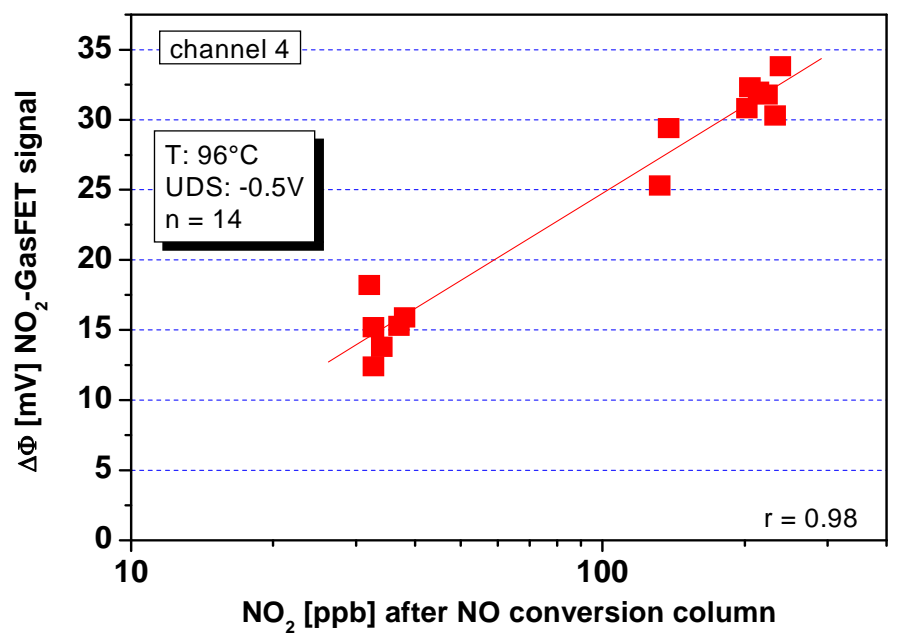

\subsection{Field Effect Sensors: Discussion and Outlook}

The gas sensors based on suspended gate FETS are characterized by some interesting features:

o They are able to work at room temperature. This reduces the energy demand for operation and avoids thermal decomposition of instable gases at the sensing surface.

o Due to their functional principle they make direct use of surface properties, thus facilitating the preparation of materials with reproducible sensing properties.

o They enable the application of various classes of sensing materials. This enhances the chances to generate a sensing surface that has a surface chemistry that allows the direct and selective reaction with the target gas to be detected. 
Arrays with these gas sensors tend to be available. In addition, it has to be stated that the potential for new sensing layers is far from being exhausted. Due to the possibilities to incorporate existing sensing layers known from other transducers and to use even new chemical affinity systems, various new sensors will come up that are based on this platform. One tendency is the research for selective sensing layers, e.g. ones assisted by a sterical selectivity mechanism like molecular imprinted polymers (MIPS), zeolites and the newly investigated mesoporous oxides [173]. The other tendency is research on new variants of the GasFET transducers that will allow operation temperatures above the normal Si-regime [174]. In the future, this might close the gap between high-temperature operated semiconducting metal oxides and work function devices.

\section{Conclusions}

The present status report highlighted how gas sensor research prospers in Germany. Many types of sensors are under development for various applications. In addition to step-by-step improvements of conventional principles, e.g. by the application of novel materials or by understanding-driven tailoring of the sensor films, novel principles turned out to open new markets. In the field of high-temperature gas sensing, real-time in-situ diagnosis of chemical reactions, for example in combustion processes or in exhaust gas aftertreatment, is an increasing application field, in particular for potentiometric or conductometric principles. With respect to low-temperature gas sensing, novel field effect devices present a high potential to enter the market for indoor air control or medical applications.

\section{References and Notes}

1. Yamazoe, N. Toward innovations of gas sensor technology. Sens. Actuat. B-Chem. 2005, 108, 2-14.

2. Williams, D.E. Semiconducting oxides as gas-sensitive resistors. Sens. Actuat. B-Chem. 1999, 57, $1-16$.

3. Chen, Z.; Lu, C. Humidity sensors: a review of materials and mechanisms. Sens. Lett. 2005, 3, 274-295.

4. Moos, R. A brief overview on automotive exhaust gas sensors based on electroceramics. Int. J. Appl. Ceram. Technol., 2005, 2, 401-413.

5. Janke, D. A new immersion sensor for the rapid electrochemical determination of dissolved oxygen in metallic melts. Solid State Ionics 1981, 3-4, 599-604.

6. Moos R.; Schönauer D. Review: recent developments in the field of automotive exhaust gas ammonia sensing. Sens. Lett. 2008, 6, 821-825.

7. Zosel, J.; Müller, R.; Vashook, V.; Guth, U. Response behaviour of perovskites and Au/oxide composites as HC-electrodes in different combustibles. Solid State Ionics 2004, 175, 531-533.

8. Azad, A.M.; Akbar, S.A.; Mhaisalkar, S.G.; Birkefeld, L.D.; Goto, K.S. Solid-state gas sensors: a review. J. Electrochem. Soc. 1992, 139, 3690-3704.

9. Moseley, P. Solid state gas sensors. Meas. Sci. Technol. 1997, 8, 223-237.

10. Riegel, J.; Neumann, H.; Wiedenmann, H.-M. Exhaust gas sensors for automotive emission control. Solid State Ionics 2002, 152-153, 783-800. 
11. Fergus, J.W. Solid electrolyte based sensors for the measurement of CO and hydrocarbon gases. Sens. Actuat. B-Chem. 2007, 122, 683-693.

12. Guth, U.; Zosel, J. Electrochemical solid electrolyte gas sensors - hydrocarbon and NOx analysis in exhaust gases. Ionics 2004, 10, 366-377.

13. Park, CO.; Akbar, S.A.; Weppner, W. Ceramic electrolytes and electrochemical sensors. J. Mater. Sci. 2003, 38, 4639-4660.

14. Möbius, H.-H. Solid-state electrochemical potentiometric sensors for gas analysis. In Sensors; Göpel, W., Hesse, J., Zemel, J.N. Eds.; Wiley-VCH: Weinheim, Germany, 1991; pp. 1105-1124.

15. Möbius, H.-H.; Sandow, H; Hartung, R; Jakobs, S; Guth, U.; Buhrow J. Entwicklung neuer sensorsysteme mit galvanischen hochtemperatur-festelektrolytzellen. DECHEMA Monographie 1992, 126, 329.

16. Harbeck, W.; Guth, U. Ermittlung der ausbrandgrenze von gasflammen mit hilfe gaspotentiometrischer bestimmungsmethoden. Die Industriefeuerung 1990, 49, 43-57.

17. Möbius, H.-H.; Zhuk, P.P.; Jakobs, S.; Hartung, R.; Guth, U.; Sandow, H.; Vecher, A.A. Investigation of electrochemical oxygen sensors with solid electrolytes and oxide powder electrodes. Sov. Electrochem. Tranl. 1991, 26, 1235-1243.

18. Guth, U.; Hartung, R.; Jakobs, S.; Sandow, K.-P.; Westphal, D.; Oxides as an electrode material for solid electrolyte gas sensors. In Proceedings of the 1997 Joint International Meeting of The Electrochemical Society and The International Society of Electrochemistry, Paris, France, August 31-September 5 1997. See also Proceedings of Electrochemical Society 97-24 (Ionic and Mixed Conducting Ceramics), Pennington, NJ, USA, 1998; pp. 231-250.

19. Shuk, P.; Vecher, A.; Kharton, V.; Tichonova L.; Wiemhöfer, H.D.; Göpel, W.; Guth, U. Electrodes for oxygen sensors based on rate earth manganites or cobaltites. Sens. Actuat. B-Chem. 1993, 15, 401-405.

20. Sandow, K.-P.; Jakobs, S.; Thiemann, S.; Hartung, R.; Guth, U.; Schönauer, U. Dotierte lanthanchrom-mischoxide als elektrodenmaterialien für $\mathrm{ZrO}_{2}$-Festelektrolyte. GDCH-Monographie 1996, 3, 377-389

21. Shuk, P.; Bailey, E.; Guth, U. Zirconia oxygen sensors for process application: state-of-the-art sensors. Transducers 2008, 90, 174-184.

22. Guth, U. Gas sensors. In Electrochemical Dictionary; Bard, A.J., Inzelt, G., Scholz F. Eds.; Springer: Berlin Heidelberg, Germany, 2008; pp. 294-299.

23. Westphal, D.; Jakobs, S.; Guth, U. Gold-composite electrodes for hydrocarbon sensors based on YSZ solid electrolytes. Ionics 2001, 7, 182-186.

24. Miura, N.; Raisen, T.; Lu, G.; Yamazoe, N. Highly selective CO sensor using stabilized zirconia and a couple of oxide electrodes. Sens. Actuat. B-Chem. 1998, 47, 84-91.

25. Hartung, R.; Schröder, R.; Möbius, H.-H. Brenngas-sensitive gassymmetrische galvanische Zellen mit oxidionenleitenden Festelektrolyten. Z. Phys. Chem. 1981, 262, 961-966.

26. Guth, U.; Zosel, J.; Jakobs, S.; Westphal, D.; Müller, R. Au-oxide composites as HC-sensitive electrode material for mixed potential gas sensors. Solid State Ionics 2002, 152-153, 525-529.

27. Wang, J.; Elumalai, P.; Terada, D.; Hasei, M.; Miura, N. Mixed-potential-type zirconia-based NOx sensor using Rh-loaded $\mathrm{NiO}$ sensing electrode operating at high temperatures. Solid State Ionics 2006, 177, 2305-2311. 
28. Chevallier, L.; Di Bartolomeo, E.; Grilli, M L.; Mainas, M.; White, B.; Wachsman, E.D.; Traversa, E. Non-Nernstian planar sensors based on YSZ with a $\mathrm{Nb}_{2} \mathrm{O}_{5}$ electrode. Sens. Actuat. BChem. 2008, 129, 591-598.

29. Morata, A.; Viricelle, J.P.; Tarancon, A.; Dezanneau, G.; Pijolat, C.; Peiro, F.; Morante, J.R. Development and characterisation of a screen-printed mixed potential gas sensor. Sens. Actuat. BChem. 2008, 130, 561-566.

30. Miura, N.; Nakatou, M.; Zhuiykov, S. Impedancemetric gas sensor based on stabilised zirconia solid electrolyte and oxide sensing electrode for detecting total NOx at high temperature. Sens. Actuat. B-Chem. 2003, 93, 221-228.

31. Nakatou, M.; Miura, N. Detection of propene by using new-type impedancemetric zirconia based sensor attached with oxide sensing-electrode. Sens. Actuat. B-Chem. 2006, 120, 57-62.

32. Zosel, J., Franke, D.; Ahlborn, K.; Gerlach, F.; Vashook, V.; Guth, U. Perovskite related electrode materials with enhanced NO sensitivity for mixed potential sensors. Solid State Ionics 2008, 179, 1628-1631.

33. Di Bartolomeo, E.; Grilli, M L.; Traversa, E. Sensing mechanism of potentiometric gas sensors based on stabilized zirconia with oxide electrodes. J. Electrochem. Soc. 2004, 151, H133-H139.

34. Zosel, J.; Tuchtenhagen, D.; Ahlborn, K.; Guth, U. Mixed potential gas sensor with short response time. Sens. Actuat. B-Chem. 2008, 130, 326-329.

35. Plashnitsa, V.V.; Ueda, T.; Elumalai, P.; Miura, N. $\mathrm{NO}_{2}$ sensing performances of planar sensor using stabilized zirconia and thin-NiO sensing electrode. Sens. Actuat. B-Chem. 2008, 130, 231-239.

36. Nakatou, M.; Miura, N. Detection of combustible hydrogen-containing gases by using impedancemetric zirconia-based water-vapor sensor. Solid State Ionics 2005, 176, 2511-2515.

37. Miura, N.; Wang, J.; Nakatou, M.; Elumalai, P.; Hasei, M. $\mathrm{NO}_{\mathrm{x}}$ sensing characteristics of mixedpotential-type zirconia sensor using $\mathrm{NiO}$ sensing electrode at high temperatures. Electrochem. SolidState Lett. 2005, 8, H9-H11.

38. Available on line at www.zirox.de

39. Zosel, J.; Opitz, T.; Bley, T.; Guth, U. Einsatz hochempfindlicher Gassensoren für das Monitoring der Aktivität von Schimmelpilzkulturen (in German) (Application of highly sensitive gas sensors for monitoring of mould culture). Der Versuchs- und Forschungsingenieur 2006, 39, 31-37.

40. Rettig, F.; Moos, R. Direct thermoelectric gas sensors: design aspects and first gas sensors. Sens. Actuat. B-Chem. 2007, 123, 413-419.

41. Rettig, F.; Moos, R. Temperature modulated direct thermoelectric gas sensors: thermal modeling and results for fast hydrocarbon sensors. Meas. Sci. Technol. 2009, $20,065205$.

42. Moos, R.; Gnudi, A.; Härdtl, K.H. Thermopower of $\mathrm{Sr}_{1-\mathrm{x}} \mathrm{La}_{\mathrm{x}} \mathrm{TiO}_{3}$ ceramics. J. Appl. Phys. 1995, $78,5042-5047$.

43. Jonker, G.H. Application of combined conductivity and seebeck-effect plots for analysis of semiconductor properties. Philips Res. Rep. 1968, 23, 131-138.

44. Moos, R. Verfahren und Meßwandler zur Detektion des Sauerstoffgehaltes in einem Gas. German Patent Specification, DE 19853595 C1, 1998. (see also: Method and Apparatus for Detecting the Oxygen Content of a gas. US Patent Specification, US 6,368,868, 2002). 
45. Ionescu, R. Combined seebeck and resistive $\mathrm{SnO}_{2}$ gas sensors, a new selective device. Sens. Actuat. B-Chem. 1998, 48, 392-394.

46. Liess, M; Steffes, H. The modulation of thermoelectric power by chemisorption - a new detection principle for microchip chemical sensors. J. Electrochem. Soc. 2000, 147, 3151-3153.

47. Moos, R.; Härdtl, K.H. Dependence of the intrinsic conductivity minimum of $\mathrm{SrTiO}_{3}$ ceramics on the sintering atmosphere. J. Amer. Ceram. Soc. 1995, 78, 2569-2571.

48. Choi, G.M.; Tuller, H.L. Defect structure and electrical properties of single-crystal $\mathrm{Ba}_{0.03} \mathrm{Sr}_{0.97} \mathrm{TiO}_{3}$. J. Amer. Ceram. Soc. 1988, 71, 201-205.

49. Moos, R.; Menesklou, W.; Schreiner, H.J.; Härdtl, K.H. Materials for temperature independent resistive oxygen sensors for combustion exhaust gas control. Sens. Actuat. B-Chem. 2000, 67, 178-183.

50. Sahner, K.; Schönauer, D.; Matam, M.; Post, M.; Moos, R. Selectivity enhancement of p-type semiconducting hydrocarbon sensors - The use of sol precipitated nano-powders. Sens. Actuat. BChem. 2008, 130, 470-476.

51. Rettig, F.; Moos, R. Morphology dependence of thermopower and resistance in semiconducting oxides with space charge regions. Solid State Ionics 2008, 179, 2299-2307.

52. Rettig, F.; Moos, R. Direct thermoelectric hydrocarbon gas sensors based on $\mathrm{SnO}_{2}$. IEEE Sensors J. 2007, 7, 1490-1496.

53. Ahlgren, E.O.; Poulsen F.W. Thermoelectric power of stabilized zirconia. Solid State Ionics 1995, 82, 193-201.

54. Röder-Roith, U.; Rettig, F.; Röder, T.; Janek, J.; Moos, R.; Sahner, K. Thick-film solid electrolyte oxygen sensors using the direct ionic thermoelectric effect. Sens. Actuat. B-Chem. 2009, 136, 530-535.

55. Stetter, J.R.; Li, J. Amperometric gas sensors - A review. Chem. Rev. 2008, 108, 352-366.

56. Turner, A.P.F.; Karube, I.; Wilson, G.S. Biosensors: Fundamentals and Applications; Oxford University Press: Oxford, U.K., 1987.

57. Mitsubayashi, K.; Yokoyama, K.; Takeuchi, T.; Karube, I. Gas-phase biosensor for ethanol. Anal. Chem. 1994, 66, 3297-3302.

58. Mitsubayashi, K.; Nishio, G.; Sawai, M.; Saito, T.; Kudo, H.; Saito, H.; Otsuka, K.; Noguer, T.; Marty, J.L. A bio-sniffer stick with FALDH (formaldehyde dehydrogenase) for convenient analysis of gaseous formaldehyde. Sens. Actuat. B-Chem. 2008, 130, 32-37.

59. Achmann, S.; Hämmerle, M.; Moos, R. Amperometric enzyme-based biosensor for direct detection of formaldehyde in the gas phase: Dependence on electrolyte composition. Electroanalysis 2008, 20, 410-417.

60. Hämmerle, M.; Achmann, S.; Moos, R. Gas diffusion electrodes for use in an amperometric enzyme biosensor. Electroanalysis 2008, 20, 2279-2286.

61. Achmann, S.; Hämmerle, M.; Moos, R. Amperometric enzyme-based gas sensor for formaldehyde: Impact of possible interferences. Sensors 2008, 8, 1351-1365.

62. Achmann, S.; Hämmerle, M.; Kita, J.; Moos, R. Miniaturized low temperature co-fired ceramics (LTCC) biosensor for amperometric gas sensing. Sens. Actuat. B-Chem. 2008, 135, 89-95.

63. Heiland, G. Zum Einfluss von Wasserstoff auf die elektrische Leitfähigkeit an der Oberfläche von Zinkoxydkristallen. Z. Phys. 1957, 148, 15-27. 
64. Seiyama, T.; Kato, A.; Fujiishi, K.; Nagatani M. A new detector for gaseous components using semiconductive thin films. Anal. Chem. 1962, 34, 1502.

65. Taguchi, N. Gas-detecting device. US Patent Specification, US 3,631,436, 1956.

66. Eranna, G.; Joshi, B.; Runthala, D.; Gupta, R. Oxide materials for development of integrated gas sensors - a comprehensive review. CRC Crit. Rev. Sol. St. Mat. Sci. 2004, 29, 111-188.

67. Korotcenkov, G. Metal oxides for solid-state gas sensors: What determines our choice?. Mater. Sci. Eng. B-Solid State M. 2007, 139, 1-23.

68. Barsan, N.; Weimar, U. Understanding the fundamental principles of metal oxide based gas sensors; the example of $\mathrm{CO}$ sensing with $\mathrm{SnO}_{2}$ sensing in the presence of humidity. J. Phys. Condens. Matter 2003, 15, R813-R839.

69. Barsan, N.; Weimar, U. Conduction model of metal oxide gas sensors. J. Electroceram. 2001, 7, 143-167.

70. Barsan, N.; Koziej, D.; Weimar, U. Metal oxide based gas sensor research: how to?. Sens. Actuat. B-Chem. 2007, 121, 18-35.

71. Kappler, J.; Tomescu, A.; Barsan, N.; Weimar, U. CO consumption of Pd doped $\mathrm{SnO}_{2}$ based sensors. Thin Solid Films 2001, 391, 186-91.

72. Emiroglu, S.; Barsan, N.; Weimar, U.; Hoffmann V. In situ diffuse reflectance infrared spectroscopy study of CO adsorption on $\mathrm{SnO}_{2}$. Thin Solid Films 2001, 391, 176-185.

73. Harbeck, S.; Szatvanyi, A.; Barsan, N.; Weimar, U.; Hoffmann, V. DRIFT studies of thick film un-doped and Pd-doped $\mathrm{SnO} 2$ sensors: temperature changes effect and $\mathrm{CO}$ detection mechanism in the presence of water vapour. Thin Solid Films 2003, 436, 76-83.

74. Sahm, T.; Gurlo, A.; Barsan, N.; Weimar, U.; Madler, L. Fundamental studies on $\mathrm{SnO}_{2}$ by means of simultaneous work function change and conduction measurements. Thin Solid Films 2005, 490, 43-47.

75. Koziej, D.; Barsan, N.; Weimar, U.; Szuber, J.; Shimanoe, K.; Yamazoe, N. Water-oxygen interplay on tin dioxide surface: Implication on gas sensing. Chem. Phys. Lett. 2005, 410, 321323.

76. Sahm, T.; Mädler, L.; Gurlo, A.; Barsan, N.; Pratsinis, S.E.; Weimar, U. Flame spray synthesis of tin dioxide nanoparticles for gas sensing. Sens. Actuat. B-Chem. 2004, 98, 148-153.

77. Schmid, W.; Barsan, N.; Weimar, U. Sensing of hydrocarbons and CO in low oxygen conditions with tin dioxide sensors: possible conversion paths. Sens. Actuat. B-Chem. 2004, 103, 362-368.

78. Schmid, W.; Barsan, N.; Weimar, U. Sensing of hydrocarbons with tin oxide sensors: possible reaction path as revealed by consumption measurements, Sens. Actuat. B-Chem. 2003, 89, 232236.

79. Bertrand, J.; Koziej, D.; Barsan, N.; Viricelle, J.P.; Pijolat C.; Weimar, U. Influence of the nature of the electrode on the sensing performance of $\mathrm{SnO}_{2}$ sensors; Impedance spectroscopy studies. Eurosensors XX 2006, 100-101.

80. Bertrand, J.; Viricelle, J.P.; Pijolat, C.; Haensch, A.; Koziej, D.; Barsan, N.; Weimar, U. $\mathrm{Metal} / \mathrm{SnO}_{2}$ interface effects on $\mathrm{CO}$ sensing; operando studies. In IEEE Sensors, Proceedings of the $6^{\text {th }}$ IEEE Sensors Conference; Atlanta, GA, USA, October 2007; pp. 492-495.

81. Gurlo, A.; Barsan, N.; Oprea, A.; Sahm, M.; Sahm, T.; Weimar, U. An n- to p-type conductivity transition induced by oxygen adsorption on alpha-Fe $\mathrm{O}_{3}$. Appl. Phys. Lett. 2004, 85, 2280-2282. 
82. Pokhrel, S.; Simion, C.E.; Quemener, V.; Barsan, N.; Weimar, U. Investigations of conduction mechanism in $\mathrm{Cr}_{2} \mathrm{O}_{3}$ gas sensing thick films by ac impedance spectroscopy and work function changes measurements. Sens. Actuat. B-Chem. 2008, 133, 78-83.

83. Hernandez-Ramirez, F.; Prades, J.D.; Tarancon, A.; Barth, S.; Casals, O.; Jiménez-Diaz, R.; Pellicer, E.; Rodriguez, J.; Juli, M.A.; Romano-Rodriguez, A.; Morante, J.R.; Mathur, S.; Helwig, A.; Spannhake, J.; Mueller, G. Portable microsensors based on individual $\mathrm{SnO}_{2}$ nanowires. Nanotechnology 2007, 18, 495501.

84. Hernandez-Ramirez, F.; Prades, J.D.; Tarancon, A.; Barth, S.; Casals, O.; Jiménez-Diaz, R.; Pellicer, E.; Rodriguez, J.; Morante, J.R.; Juli, M.A.; Mathur, S.; Romano-Rodriguez, A. Insight into the role of oxygen diffusion in the sensing mechanisms of $\mathrm{SnO}_{2}$ nanowires. Adv. Funct. Mater. 2008, 18, 2990-2994.

85. Polleux, J.; Gurlo, A.; Barsan, N.; Weimar, U.; Antonietti, M.; Niederberger, M. Template-free synthesis and assembly of single-crystalline tungsten oxide nanowires and their gas-sensing properties. Angew. Chem. Int. Ed. 2006, 45, 261-265.

86. Yannopoulos, L.N. A p-type semiconducting thick film gas sensor. Sens. Actuat. 1987, 12, 263273.

87. Carotta, M.C.; Martinelli, G.; Sadaoka, Y.; Nunziante, P.; Traversa, E. Gas-sensitive electrical properties of perovskite-type $\mathrm{SmFeO}_{3}$ thick films. Sens. Actuat. B-Chem. 1998, 48, 270-276.

88. Morrison, S. R. Selectivity in semiconductor sensors. In Proceedings of the $2^{\text {nd }}$ International Meeting on Chemical Sensors (IMCS), Bordeaux, France, July 1986.

89. Moseley, P.; Williams, D.E. Gas sensors based on oxides of early transition metals. Polyhedron 1989, 8, 1615-1618.

90. Niemeyer, D.; Williams, D.E.; Smith, P.; Pratt, K.F.; Slater, B.; Catlow, C.R.A.; Stoneham, A.M. Experimental and computational study of the gas-sensor behaviour and surface chemistry of the solid-solution $\mathrm{Cr}_{2-\mathrm{x}} \mathrm{Ti}_{\mathrm{x}} \mathrm{O}_{3}(\mathrm{x}<0.5)$. J. Mater. Chem. 2002, 12, 666-675.

91. Aono, H.; Traversa, E.; Sakamoto, M.; Sadaoka, Y. Crystallographic characterization and $\mathrm{NO}_{2}$ gas sensing property of $\mathrm{LnFeO}_{3}$ prepared by thermal decomposition of $\mathrm{Ln}-\mathrm{Fe}$ hexacyanocomplexes, $\mathrm{Ln}\left[\mathrm{Fe}(\mathrm{CN})_{6}\right] \cdot n \mathrm{H}_{2} \mathrm{O}, \mathrm{Ln}=\mathrm{La}, \mathrm{Nd}, \mathrm{Sm}, \mathrm{Gd}$, and Dy. Sens. Actuat. B-Chem. 2003, 94, 132-139.

92. Moos, R.; Rettig, F.; Hürland, A.; Plog, C. Temperature-independent resistive oxygen exhaust gas sensors for lean-burn engines in thick-film technology. Sens. Actuat. B-Chem. 2003, 93, 43-50.

93. Rothschild, A.; Litzelmann, S. J.; Tuller, H.L.; Menesklou, W.; Schneider, T.; Ivers-Tiffée, E. Temperature-independent resistive oxygen sensors based on $\mathrm{SrTi}_{1-\mathrm{x}} \mathrm{Fe}_{\mathrm{x}} \mathrm{O}_{3-\delta}$ solid solutions. Sens. Actuat. B-Chem. 2005, 108, 223-230.

94. Rettig, F.; Moos, R.; Plog, C. Sulfur adsorber for thick-film exhaust gas sensors. Sens. Actuat. BChem. 2003, 93, 36-42.

95. Rettig, F.; Moos, R.; Plog, C. Poisoning of temperature independent resistive oxygen sensors by sulfur dioxide. J. Electroceram. 2004, 13, 733-738.

96. Blase, R.; Härdtl, K.H.; Schönauer, U. Oxygen Sensor based on non-doped cuprate. United States Patent Specification, US 5,792,666, 1997.

97. Moos, R.; Rettig, F. Resistiver sauerstoffsensor (Resistive Oxygen Sensor), German Patent Specification, DE 10114645 C1, 2003. 
98. Sahner, K.; Moos, R.; Izu, N.; Shin, W.; Murayama, N. Response kinetics of temperature independent resistive oxygen sensor formulations: a comparative study. Sens. Actuat. B-Chem. 2006, 113, 112-119.

99. Sahner, K.; Straub, J.; Moos, R. Cuprate-ferrate compositions for temperature independent resistive oxygen sensors. J. Electroceram. 2006, 16, 179-186.

100. Sahner, K.; Moos, R.; Matam, M.; Tunney, J.; Post, M. Hydrocarbon sensing with thick and thin film p-type conducting perovskite materials. Sens. Actuat. B-Chem. 2005, 108, 102-112.

101. Sahner, K.; Schönauer, D.; Moos, R.; Matam, M.; Post, M.L. Effect of electrodes and zeolite cover layer on hydrocarbon sensing with p-type perovskite $\operatorname{SrTi}_{0.8} \mathrm{Fe}_{0.2} \mathrm{O}_{3-\delta}$ thick and thin films. $J$. Mater. Sci. 2006, 41, 5828-5835.

102. Sahner, K.; Gouma, P.; Moos, R. Electrodeposited and sol-gel precipitated p-type $\mathrm{SrTi}_{1-\mathrm{x}} \mathrm{Fe}_{\mathrm{x}} \mathrm{O}_{3-\delta}$ semiconductors for gas sensing. Sensors 2007, 7, 1871-1886.

103. Sahner, K.; Moos, R. Modeling of hydrocarbon sensors based on p-type semiconducting perovskites. Phys. Chem. Chem. Phys. 2007, 9, 635-642.

104. Sahner, K.; Moos, R. P-type semiconducting perovskite sensors for reducing gases - model description. Sens. Lett. 2008, 6, 808-811.

105. Weitkamp, J. Zeolites and catalysis. Solid State Ionics 2000, 131, 175-188.

106. Sahner, K.; Hagen, G.; Schönauer, D.; Reiß, S.; Moos, R. Zeolites - Versatile materials for gas sensors. Solid State Ionics 2008, 179, 2416-2423.

107. Xu, X.; Wang, J.; Long, Y. Zeolite-based materials for gas sensors. Sensors 2006, 6, 1751-1764.

108. Moos, R.; Sahner, K.; Hagen, G.; Dubbe, A. Zeolites for sensors for reducing gases. Rare Metal Mat. Eng. 2006, 35 Suppl. 3, 447-451.

109. Vilaseca, M.; Coronas, J.; Cirera, A.; Cornet, A.; Morante, J.; Santamaría, J. Use of zeolite films to improve the selectivity of reactive gas sensors. Catal. Today 2003, 82, 179-185.

110. Hugon, O.; Sauvan, M.; Benech, P.; Pijolat, C.; Lefebvre, F. Gas separation with a zeolite filter, application to the selectivity enhancement of chemical sensors. Sens. Actuat. B-Chem. 2000, 67, 235-243.

111. Sahner, K.; Schönauer, D.; Kuchinke, P.; Moos, R. Zeolite cover layer for selectivity enhancement of p-type semiconducting hydrocarbon sensors. Sens. Actuat. B-Chem. 2008, 133, 502-508.

112. Meier, B.; Werner, T.; Klimant, I.; Wolfbeis, O.S. Novel oxygen sensor material based on a ruthenium bipyridil complex encapsulated in zeolite $\mathrm{Y}$ - dramatic differences in the efficiency of luminescence quenching by oxygen on going from surface-adsorbed to zeolite-encapsulated flurophores. Sens. Actuat. B-Chem. 1995, 29, 240-245.

113. Nischwitz, P.; Amels, P.; Fetting, F. Studies on the ionic conductivity of zeolitic solids. Solid State Ionics 1994, 73, 105-118.

114. Plog, C.; Maunz, W.; Kurzweil, P.; Obermeier, E.; Scheibe C. Combustion gas sensitivity of zeolite layers on thin-film capacitors. Sens. Actuat. B-Chem. 1995, 24-25, 403-406.

115. Schäf, O.; Ghobarkar, H.; Guth, U. Sensors for combustible gas components using modified single crystal zeolites. Ionics 1997, 3, 282-288.

116. Schäf, O.; Ghobarkar, H.; Steinbach, A.C.; Guth, U. Basic investigations on zeolite application for electrochemical analysis. Fresenius J. Anal. Chem. 2000, 367, 388-392. 
117. Neumeier, S.; Echterhof, T.; Bölling, R.; Pfeifer, H.; Simon, U. Zeolite based trace humidity sensor for high temperature applications in hydrogen atmosphere. Sens. Actuat. B-Chem. 2008, 134, 171-174.

118. Simon, U.; Flesch, U.; Maunz, W.; Müller, R.; Plog, C. The effect of $\mathrm{NH}_{3}$ on the ionic conductivity of dehydrated zeolites $\mathrm{Na}$ beta and $\mathrm{H}$ beta. Micropor. Mesopor. Mat. 1998, 21, 111 116.

119. Franke, M.; Simon, U.; Moos, R.; Knezevic, A.; Müller, R.; Plog, C. Development and working principle of an ammonia gas sensor based on a refined model for solvate supported proton transport in zeolites. Phys. Chem. Chem. Phys. 2003, 5, 5195-5198.

120. Moos, R.; Müller, R.; Plog, C.; Knezevic, A.; Leye, H.; Irion, E.; Braun, T.; Marquardt, K.; Binder, K. Selective ammonia exhaust gas sensor for automotive applications, Sens. Actuat. BChem. 2002, 83, 181-189.

121. Rodriguez-Gonzalez, L.; Franke, M.; Simon, U. Electrical detection of different amines with proton-conductive H-ZSM-5. Molecular Sieves: from basic research to industrial applications 2005, Pts. A and B 158, 2049-2056.

122. Schönauer, D.; Sichert, I.; Moos, R. Zeolithe zur Ammoniakdetektion in Abgasen. Z. Anorg. Allg. Chem. 2008, 634, 2077.

123. Tennison, P.; Lambert, C.; Levin, M. NOx control development with urea SCR on a diesel passenger car; SAE 2004-01-1291; SAE: Miami, 2004.

124. Hagen, G.; Dubbe, A.; Rettig, F.; Jerger, A.; Birkhofer, T.; Müller, R.; Plog, C.; Moos, R. Selective impedance based gas sensors for hydrocarbons using ZSM-5 zeolite films with chromium(III)oxide interface. Sens. Actuat. B-Chem. 2006, 119, 441-448.

125. Hagen, G.; Schulz, A.; Knörr, M.; Moos, R. Four-wire impedance spectroscopy on planar zeolite/chromium oxide based hydrocarbon gas sensors. Sensors 2007, 7, 2681-2692.

126. Reiß S.; Hagen G.; Moos R. Zeolite-based Impedimetric Gas Sensor Device in Low-cost Technology for Hydrocarbon Gas Detection. Sensors 2008, 8, 7904-7916.

127. Fischerauer, A.; Gollwitzer, A.; Thalmayr, F.; Hagen, G.; Moos, R.; Fischerauer, G. An initial physics-based model for the impedance spectrum of a hydrocarbon sensor with a zeolite $/ \mathrm{Cr}_{2} \mathrm{O}_{3}$ interface. Sens. Lett. 2008, 6, 1019-1022.

128. Achmann, S.; Hagen, G.; Kita, J.; Malkowsky, I.M.; Kiener, C.; Moos, R. Metal-organic frameworks for sensing applications in the gas phase. Sensors 2009, 9, 1574-1589.

129. Sauerwald, T.; Skiera, D.; Kohl, C.-D. Selectivity enhancement of gas sensors using nonequilibrium polarisation effects in metal oxide films. Appl. Phys. A 2007, 87, 525-529.

130. Waitz, T.; Wagner, T.; Sauerwald, T.; Kohl, C.-D.; Tiemann, M. Ordered mesoporous $\operatorname{In}_{2} \mathrm{O}_{3}$ : synthesis by structure replication and application as a methane gas sensor. Adv. Funct. Mater. 2009, 19, 653-661.

131. Wagner, T.; Sauerwald, T.; Kohl, C.-D.; Waitz, T.; Weidmann, C.; Tiemann, M. Gas sensor based on ordered mesoporous $\mathrm{In}_{2} \mathrm{O}_{3}$. Thin Solid Films 2009. In press, DOI: 10.1016/j.tsf.2009.04.013.

132. Wessels, J.M.; Nothofer, H.-G.; Ford, W.E.; von Wrochem, F.; Scholz, F.; Vossmeyer, T.; Schroedter, A.; Weller, H.; Yasuda, A. Optical and electrical properties of three-dimensional interlinked gold nanoparticle assemblies. J. Amer. Chem. Soc. 2004, 126, 3349-3356. 
133. Joseph, Y.; Guse, B.; Yasuda, A.; Vossmeyer, T. Chemiresistor coatings from Pt- and Aunanoparticle/nonanedithiol films: sensitivity to gases and solvent vapors. Sens. Actuat. B-Chem. 2005, 98, 188-195.

134. Krasteva, N.; Fogel, Y.; Bauer, R.E.; Müllen, K.; Joseph, Y.; Matsuzawa, N.; Yasuda, A.; Vossmeyer, T. Vapor sorption and electrical response of Au-nanoparticle-dendrimer composites, Adv. Funct. Mater. 2007, 17, 881-888.

135. Sahner, K.; Tuller, H.L. Novel deposition techniques for metal oxides: prospects for gas sensing. J. Electroceram. 2009. In press, DOI: 10.1007/s10832-008-9554-7.

136. Mädler, L.; Sahm, T.; Gurlo, A.; Barsan, N.; Grunwald, J.D.; Weimar, U.; Pratsinis, S.E. Sensing low concentrations of $\mathrm{CO}$ using flame-spray-made $\mathrm{Pt} / \mathrm{SnO}_{2}$ nanoparticles. J. Nanoparticle Res. 2006, 8, 783-796

137. Sahm, T.; Rong, W.; Barsan, N.; Mädler, L.; Weimar, U. Sensing of $\mathrm{CH}_{4}, \mathrm{CO}$ and ethanol with in situ nanoparticle aerosol-fabricated multilayer sensors. Sens. Actuat. B-Chem. 2007, 127, 63-68.

138. Sahner K.; Kaspar, M.; Moos, R. Assessment of the aerosol deposition method for preparing metal oxide gas sensors at room temperature. Sens. Actuat. B-Chem. 2009, 139, 394-399.

139. Akedo, J.; Lebedev, M. Microstructure and electrical properties of lead zirconate titanate $\left(\mathrm{Pb}\left(\mathrm{Zr}_{0.52} \mathrm{Ti}_{0.48}\right) \mathrm{O}_{3}\right)$ thick film deposited with aerosol deposition method. Jpn. J. Appl. Phys. 1999, 38, 5397-5401.

140. Koplin, T.J.; Siemons, M.; Océn-Valéntin, C.; Sanders, D.; Simon, U. Workflow for high throughput screening of gas sensing materials. Sensors 2006, 6, 298-307.

141. Frenzer, G.; Frantzen, A.; Sanders, D.; Simon, U.; Maier, W.F. Wet chemical synthesis and screening of thick porous oxide films for resistive gas sensing applications. Sensors 2006, 6 , 1568-1586.

142. Siemons, M.; Leifert, A.; Simon, U. Preparation and gas sensing characteristics of nanoparticulate p-type semiconducting $\mathrm{LnFeO}_{3}$ and $\mathrm{LnCrO}_{3}$ materials. Adv. Funct. Mater. 2007, 17, 2189-2197.

143. Siemons, M.; Koplin, T.J.; Simon, U. Advances in high throughput screening of gas sensing materials. Appl. Surf. Sci. 2007, 254, 669-676.

144. Lundtström, I.; Shivaraman, M.S.; Svenson, C.M. Hydrogen-sensitive Pd-gate MOS-transistor. J. Appl. Phys. 1975, 46, 3876-3881.

145. Zhang, T.H.; Petelenz, D.; Janata, J. Temperature-controlled Kelvin microprobe. Sens. Actuat. BChem. 1993, 12, 175-180.

146. Lorenz, H.; Perschke, M.; Riess, H.; Janata, J.; Eisele, I. New suspended gate FET technology, for physical deposition of chemically sensitive layers. Sens. Actuat. A-Phys. 1990, 23, 10231026.

147. Flietner, B.; Doll, T.; Eisele, I. Reliable hybrid GasFETs for work-function measurements with arbitrary materials. Sens. Actuat. B-Chem. 1994, 22, 109-113.

148. Gergintschew, Z.; Kornetzky, P.; Schipanski, D. The capacitively controlled field effect transistor (CCFET) as a new low power gas sensor. Sens. Actuat. B-Chem. 1996, 35-36, 285-289.

149. Pohle, R.; Simon, E.; Fleischer, M.; Meixner, H.; Frerichs, H.-P.; Lehmann, M.; Verhoeven, H. Realisation of a new sensor concept: improved CCFET and SGFET type gas sensors in hybrid flip-chip technology. In Actuators and Microsystems, Proceedings of the $12^{\text {th }}$ International 
Conference on Solid-State Sensors, Actuators and Microsystems, TRANSDUCERS 2003, June 2003; pp.135-138.

150. Fleischer, M.; Ostrick, B.; Pohle, R.; Simon, E.; Meixner, H.; Bilger, C.; Daeche, F. Low-power gas sensors based on work function measurement in low-cost hybrid flip-chip technology. Sens. Actuat. B-Chem. 2001, 80, 169-173.

151. Schneider, R.; Fleischer, M.; Lampe, U.; Pohle, R.; Simon, E. Integrated sensor array based on field effect transistors for the detection of different gas components. In Proceedings of Eurosensors, Barcelona, Spain, September 2005.

152. Ostrick, B.; Pohle, R.; Fleischer, M.; Meixner, H. TiN in Workfunction Type Sensors: A stable ammonia sensitive material for room temperature operation with low humidity cross sensitivity. Sens. Actuat. B-Chem. 2000, 68, 234-239.

153. Oprea, A.; Simon, E.; Fleischer, M.; Lehmann, M.; Frerichs, H.-P.; Weimar, U. Flip-chip suspended gate field effect transistor for ammonia detection. Sens. Actuat. B-Chem. 2005, 111112, 582-586.

154. Eisele, I.; Doll, T.; Burgmair, M. Low power gas detection with FET sensors. Sens. Actuat. BChem. 2001, 78, 19-25.

155. Scharnagl, K.; Eriksson, M.; Karthigeyan, A.; Burgmair, M.; Zimmer, M.; Eisele I. Hydrogen detection at high concentrations with stabilised palladium. Sens. Actuat. B-Chem. 2001, 78, 138143.

156. Senft, C.; Galonska, T.; Widanarto, W.; Frerichs, H-P.; Wilbertz, C.; Eisele, I. Stability of FET based hydrogen sensors at high temperatures. In Proceedings of IEEE Sensors 2007 Conference, Atlanta, Georgia, October 2007; pp.189-192. DOI: 10.1109/ICSENS.2007.4388368

157. Zimmer, M.; Burgmair, M.; Scharnagl, K.; Karthigeyan, A.; Doll, T.; Eisele, I. Gold and platinum as ozone sensitive layer in work-function gas sensors. Sens. Actuat. B-Chem. 2001, 80, 174-178.

158. Sulima, T.; Knittel, T.; Freitag, G.; Widanarto W.; Eisele, I. A gas FET for chlorine detection. In Proceedings of IEEE Sensors 2005 Conference, Irvine, California, October-November 2005. DOI: 10.1109/ICSENS.2005.1597649

159. Stegmeier, S. Nanotechnologische Schichten zur Detektion von flüchtigen Kohlenwasserstoffen mit SGFET- Gassensoren, Bachelor Thesis, University of Applied Science, Munich, 2007.

160. Stegmeier, S.; Hauptmann, P.; Fleischer, M. Room temperature detection of VOCs with activated platinum and supported platinum sensing layers by the change of work function. In Proceedings of Eurosensors 2008, Dresden, Germany, September 2008.

161. Kiss, G.; Josepovits, V.K.; Kovacs, K.; Ostrick, B.; Fleischer, M.; Meixner, H.; Reti, F. CO Sensitivity of the $\mathrm{PtO} / \mathrm{SnO} 2$ and $\mathrm{PdO} / \mathrm{SnO} 2$ layer structures. Kelvin probe and XPS analysis. In Proceedings of Eurosensors XVI, Prague, September 2002.

162. Lampe, U.; Simon, E.; Pohle, R.; Fleischer, M.; Meixner, H.; Frerichs, H.-P.; Lehmann, M.; Kiss, G. GasFET for the detection of reducing gases. Sens. Actuat. B-Chem. 2005, 111-112, 106-110.

163. Ostrick, B.; Mühlsteff, J.; Fleischer, M.; Meixner, H.; Doll, T.; Kohl C.-D. Adsorbed water as key to room temperature gas-sensitive reactions in work function type gas sensors: the carbonate carbon dioxide system. Sens. Actuat. B-Chem. 1999, 57, 115-119. 
164. Ostrick, B.; Fleischer, M.; Meixner, H.; Kohl, C.-D. Investigation of the reaction mechanisms, in work function type gas sensors at room temperature by studies of the cross sensitivity to oxygen and water: the carbonate-carbon dioxide system. Sens. Actuat. B-Chem. 2000, 68, 197-202.

165. Ostrick, B.; Fleischer, M.; Meixner, H. The influence of interfaces and interlayers on the gas sensitivity in work function type sensors. Sens. Actuat. B-Chem. 2003, 95, 271-274.

166. Simon, E.; Lampe, U.; Pohle, R.; Fleischer, M.; Meixner, H.; Frerichs, H.-P.; Lehmann, M.; Verhoeven, H. Novel carbon dioxide gas sensors based on field effect transistors. In Proceedings of the $12^{\text {th }}$ Transducers 2003, Boston, USA, June 2003.

167. Stegmaier, S.; Fleischer, M.; Hauptmann, P. Detection of VOC with activated Pt and supported Pt sensing layers by the change of work function at room temperature. In Proceedings of Eurosensors 2009, Lausanne, Switzerland, September 2009.

168. Simon, E.: Fleischer, M.; Meixner, H. Polyvinylpyrrolidone, a new material for humidity sensors using workfunction readout. In Proceedings of the $8^{\text {th }}$ International Meeting on Chemical Sensors, Basel, Switzerland, July 2000.

169. Jones, S.L.; Kittelson, J.; Cowan, J.O.; Flannery, E.M.; Hancox, R.J.; Mclachlan, C.R.; Taylor, D.R. The predictive value of exhaled nitric oxide measurements in assessing changes in asthma control. Am. J. Respir. Crit. Care Med. 2001, 164, 738-43.

170. Simon, E.; Fleischer, M.; Meixner, H. Porhin-dyes-high potential $\mathrm{NO}_{2}$-layers for asthma detection in breath in workfunction type gas sensors, In Proceedings of Eurosensors XVI, Prague, September 2002.

171. Fleischer, M.; Simon, E.; Rumpel, E.; Ulmer, H.; Harbeck, M.; Wandel, M.; Fietzek, C.; Weimar, U.; Meixner, H. Detection of volatile compounds correlated to human diseases through breath analysis with chemical sensors. Sens. Actuat. B-Chem. 2002, 83, 245-249.

172. Weimar, U.; Simon, E.; Fleischer, M.; Frerichs, H.-P.; Wilbertz C.; Lehmann, M. Copper phthalocyanine suspended gate field effect transistors for $\mathrm{NO}_{2}$ detection. Sens. Actuat. B-Chem. 2006, 118, 249-254.

173. Waitz, T.; Wagner, T.; Sauerwald, T.; Kohl, C.-D.; Tiemann, M. Ordered mesoporous In2O3: synthesis by structure replication and application as a methane gas sensor. Adv. Funct. Mater. 2009, 19, 653-661.

174. Iskra, P.; Senft, C.; Kulaga-Egger, D.; Sulima, T.; Eisele I. A concept for a GasFET for high temperature operation. In Proceedings of IEEE Sensors 2008 Conference, Lecce, Italy, October 2008; pp. 1301-1304. DOI: 10.1109/ICSENS.2008.4716683.

(C) 2009 by the authors; licensee Molecular Diversity Preservation International, Basel, Switzerland. This article is an open-access article distributed under the terms and conditions of the Creative Commons Attribution license (http://creativecommons.org/licenses/by/3.0/). 